\title{
The use of schematic knowledge about sources in source monitoring
}

\author{
UTE J. BAYEN \\ University of North Carolina, Chapel Hill, North Carolina \\ GLENN V. NAKAMURA and SUSAN E. DUPUIS \\ University of Memphis, Memphis, Tennessee \\ and \\ CHIN-LUNG YANG \\ University of North Carolina, Chapel Hill, North Carolina
}

\begin{abstract}
Source monitoring refers to mental processes leading to attributions regarding the origin of information. We tested Johnson, Hashtroudi, and Lindsay's (1993) assumption that prior source-relevant knowledge is used in some source-monitoring tasks. In two experiments using different domains of schematic knowledge, two sources presented information that was expected for one source and somewhat unexpected for the other. In a later source-monitoring test, participants decided whether items had been presented by Source A, by Source B, or were new. The results of both experiments show that source identification is better for expected items than for somewhat unexpected items. Multinomial modeling analyses revealed that when participants do not remember the source of information, they guess that it was presented by the expected source. These results provide evidence for the claim that source monitoring can be based on prior knowledge and support a guessing hypothesis.
\end{abstract}

Source monitoring involves judgments regarding the source or origin of information. Johnson, Hashtroudi, and Lindsay (1993) have defined source monitoring as "the set of processes involved in making attributions about the origins of memories, knowledge, and beliefs" (p. 3). In a typical source-monitoring paradigm, research participants are presented with items that originate from different sources. At test, they are presented with target items that originated from different sources and with distractor items, and are instructed to decide whether a given item was presented at study and from which source it originated. Sources in a source-monitoring task can be different speakers, different presentation media or modalities, any context in which information was presented, or any attribute of information (such as its color or font). Johnson's theoretical framework of source monitoring (Johnson,

The research reported in this article was supported by a Junior Faculty Development Award and a University Research Council Grant from the University of North Carolina at Chapel Hill, and a Mason and Linda Stephenson Faculty Award from the Department of Psychology at the University of North Carolina at Chapel Hill. We thank Destiny Shellhammer for conducting the norming study and computer programming for Experiment 1. We thank Jill Zukerman, Erica Snider, Richard Carroll, Michelle Burt, and Jessica Webb for their assistance with data collection. We thank Kristi Multhaup, Julia Spaniol, Neil Bearden, Marcia Johnson, and two anonymous reviewers for comments on earlier versions of the manuscript. Correspondence should be addressed to U. J. Bayen, Department of Psychology, University of North Carolina at Chapel Hill, Davie Hall, CB\#3270, Chapel Hill, NC 27599 (e-mail: ubayen@unc.edu). 1997a, 1997b; Johnson et al., 1993; Johnson \& Raye, 1981) has been used to guide source-monitoring research and to account for the results that have emerged from such research. An important component of this framework is that source monitoring sometimes relies on the use of judgment processes that are based on prior knowledge. To date this theoretical assumption has received very little research attention. Thus, the purpose of the present study was to empirically test whether or not people rely on prior knowledge in their source judgments, and if they do, which kinds of cognitive processes are involved in the use of prior knowledge.

Since the seminal work by Johnson and collaborators (Johnson \& Raye, 1981), research on source monitoring has enjoyed increasing popularity in various fields of psychological inquiry (for a review, see Johnson et al., 1993). Johnson's theoretical framework identifies the types of information and the cognitive processes that are utilized in source-monitoring tasks (Johnson, 1997a, 1997b; Johnson et al., 1993; Johnson \& Raye, 1981). According to this framework, responses in these tasks are "based on characteristics of memories in combination with judgment processes" (Johnson et al., 1993, p. 4). The characteristics of memories and judgment processes based on prior knowledge are two major components of the framework.

Characteristics of memories can be perceptual information (e.g., sources are perceptually distinct from each other), spatial information (e.g., two sources are in different corners of a room), temporal information (e.g., information was given today vs. yesterday), affective infor- 
mation (e.g., emotional reactions that different sources evoke), or memory for cognitive operations that took place at the time of encoding. Such source characteristics are encoded along with the information, and at the time of retrieval they are potential cues to the source. A large number of research studies have provided empirical support for the hypothesis that source monitoring is easier when the sources are distinct with regard to their characteristics (for a review, see Johnson et al., 1993).

According to Johnson's theoretical framework, source monitoring sometimes involves judgment processes beyond the evaluation of phenomenal characteristics of episodic memories. Some of these judgment processes involve the use of prior knowledge of sources and contexts. For example, a person may think, "Does this seem plausible, given other things that I know?" (Johnson et al., 1993, p. 4). The person might reason, "Sam was the only person there who would have said this sort of thing, so he must have said it" (Johnson et al., 1993, p. 4), or, "you may decide you read something in the newspaper rather than saw it on TV news because you remember thinking it was consistent with the newspaper's position" (Johnson, 1997b, p. 1734).

Although such judgment processes based on prior knowledge are an important component of Johnson's theoretical framework, empirical evidence for these processes is still scarce. Johnson, Foley, Suengas, and Raye (1988, Experiment 2) asked participants how they knew whether the sources of their autobiographical memories were real events or imagination. A large number of participants reported that they drew on general knowledge to make such source judgments, for example, "[This must be a fantasy because] I was too young to be a doctor" (Johnson et al., 1988, p. 374). The issue of prior knowledge in source monitoring was also investigated by Hyman, Husband, and Billings (1995), who used a paradigm in which individuals were induced to "remember" autobiographical events that the experimenters suggested had happened to them. Participants who reported background knowledge that made a suggested false childhood event appear plausible were later more likely to report that the event had really happened than those participants whose background knowledge did not fit in with the event. For example, if participants remember a birthday party when appearance of a clown is suggested, they may later falsely recall that there was a clown at the party. Hyman et al. concluded that accessing relevant prior knowledge plays a significant role in the creation of "false memories" and in source confusions-that is, errors in the discrimination of events that really happened and events that were suggested by others.

These studies suggest that people rely on prior knowledge in everyday source-monitoring tasks. However, to date no experimental research has been performed that systematically manipulates the degree to which combinations of source and originating information conform to prior knowledge. Such research would be necessary to provide empirical evidence for reliance on such knowl- edge in source monitoring. ${ }^{1}$ Experimental studies on source monitoring are usually designed in such a way that it is impossible for the participant to draw on prior knowledge. In standard laboratory source-monitoring studies involving external sources, the participants have no prior knowledge of the sources. For example, two speakers may be heard that are unknown to the participant and do not give any indication as to their social role, character, opinions, and so forth (Bornstein \& LeCompte, 1995; Glisky, Poster, \& Routhieaux, 1995; Johnson, DeLeonardis, Hashtroudi, \& Ferguson, 1995; Keefe, Arnold, Bayen, \& Harvey, 1999, to mention only a few of the many studies to which this applies). Furthermore, items are usually randomly assigned to sources so that there is no semantic relationship between a source and the information it presents. Customarily, these items merely consist of a series of unrelated words (e.g., Bornstein \& LeCompte, 1995; Keefe et al., 1999) or at most a series of trivia statements (e.g., "Elizabeth Taylor grows peaches in her orchard"; Schacter, Osowiecki, Kaszniak, Kihlstrom, \& Valdiserri, 1994; see also Erngrund, Mäntylä, \& Nilsson, 1996) that are equally plausible for any of the sources to have made. For the most part, these studies focus on the investigation of source-monitoring processes other than those related to prior knowledge. Thus, the experimental control of source-related background knowledge serves its purpose in these experiments.

However, such background knowledge is an integral part of many real-life source-monitoring tasks. In real-life situations, sources of information, such as speakers or media, are frequently known to the listener or reader, and make meaningful statements that fit with their role and the social situation. Thus, there exists a semantic relationship between sources and the contents of their message. For example, in conversations with your doctor he/she will often make statements that are highly expected for a member of his/her professional group. If you are trying to remember who told you to take a certain medication, your doctor is a very plausible source-more plausible than, for example, your lawyer or your car mechanic. Similarly, certain items are likely to appear in certain contexts. For example, imagine that you usually keep your keys in the bedroom and you are searching for them at some point. You would wonder in which room of your house you last saw them (a source-monitoring task). On the basis of your prior knowledge, you realize that the bedroom would be a plausible place to look. In most everyday situations, it is very adaptive to make source judgments based on plausibility and conformity with prior source-related knowledge. Reasoning based on prior knowledge would, in the majority of cases, lead to correct source judgments. It thus appears that the judgment processes based on prior knowledge that Johnson and her collaborators postulate might play a key role in many everyday sourcemonitoring tasks and warrant empirical investigation for applied as well as theoretical reasons.

In order to explore the role of prior knowledge in source monitoring, we designed two experiments in which two 
sources presented items that were expected for one source and somewhat unexpected for the other source. In Experiment 1 , the items were objects and the sources were scenes. In Experiment 2, the items were statements and the sources were members of professional groups. The sources and the expectancy of the information they presented were completely crossed. Each source presented half of the items. Half of the items presented by each source were expected for this source and somewhat unexpected for the other source; the other half of the items presented by each source were somewhat unexpected for this source and expected for the other source. In Experiment 2, we also included a condition in which the information was equally expected (i.e., neutral) for both sources. The degree of expectancy of item-source combinations was based on the participants' schema for a source. A schema is a knowledge structure for organizing associated concepts that is based on prior experience (Alba \& Hasher, 1983). We manipulated the degree to which the information presented was expected with regard to the schemas that underlie each of the two sources.

According to Johnson et al.'s (1993) theoretical framework of source monitoring, prior knowledge is used in source-monitoring tasks. If prior knowledge in the form of schemas is utilized in source monitoring, then expected information that fits the schema for its source should lead to better source identification than should nonschema information, such as somewhat unexpected or neutral information that does not fit the schema for its source. For example, suppose your doctor said, "You should take medicine for your headaches." This statement is expected for the doctor schema and somewhat unexpected for the lawyer schema. Later on, you will be more likely to correctly attribute this statement to your doctor as the source than in comparison with attributing this statement to your lawyer if the lawyer made this statement. We will refer to this hypothesis as the performance hypothesis, because it asserts that source-identification performance is related to the use of source-relevant schemas.

Source-identification performance depends on several cognitive processes. Correct source identification may be achieved by remembering the source on the basis of remembering particular perceptual, spatial (etc.) details, or it may be achieved by guessing the correct source in the absence of sufficient memory for such details. An important theoretical question is which of these cognitive processes play a role in the performance advantage for information that conforms to the schema of its source. Schema research has shown that people make schema-based guesses in item recognition tasks (Brewer \& Treyens, 1981; Erdfelder \& Bredenkamp, 1998; Graesser \& Nakamura, 1982; Graesser, Woll, Kowalski, \& Smith, 1980; Locksley, Stangor, Hepburn, Grosovsky, \& Hochstrasser, 1984; Nakamura, Graesser, Zimmerman, \& Riha, 1985). If a test item is part of a schema, people will sometimes guess that it occurred based on their schema even though they do not truly remember the occurrence of the item. Johnson et al.'s (1993) example "Sam was the only person there who would have said this sort of thing, so he must have said it" (p. 4) suggests that when people do not remember the source of information in a source-monitoring task, they also make guesses based on prior knowledge. We thus propose a guessing hypothesis according to which schema-based guessing processes play a major role in influencing overall source-identification performance in source-monitoring tasks. The guessing hypothesis proposes that when people cannot remember the source of information, they make guesses based on their schemas of possible sources. For example, when you remember that somebody told you to take medicine for your headaches, but you do not remember who said this, you are likely to guess that the statement originated from a source from which such a statement is expected, such as your doctor. Such schema-based guessing will boost source-identification performance if the given information is expected for its source. If, however, a source presented somewhat unexpected information, schema-based guessing may hurt performance. If the information is neutral with regard to source-related schemas, then source identification will be neither helped nor hurt by guessing, because there is no schema to guess the source.

It is conceivable that schemas influence episodic memory processes for source identification in addition to and independent of guessing. Three theoretical accounts predict better memory for unexpected than expected information if a schema is activated during encoding: the attention hypothesis, the schema-copy-plus-tag model, and the associative model. According to the attention hypothesis (Brewer \& Treyens, 1981; Friedman, 1979; G. R. Loftus \& Mackworth, 1978), objects that are unexpected in a scene receive more attention than scene-expected objects and are, therefore, remembered better. According to the schema-copy-plus-tag model (Graesser, Gordon, \& Sawyers, 1979; Graesser \& Nakamura, 1982; Graesser et al., 1980; Smith \& Graesser, 1981), unexpected information is stored in memory separate from the schema, whereas expected presented and unpresented information is interrelated in the schema. Unexpected information is thus distinctive in memory relative to expected information, leading to better memory for the unexpected information. According to the associative model of person memory (Hastie, 1980; Hastie \& Kumar, 1979; Srull, 1981; Srull, Lichtenstein, \& Rothbart, 1985), unexpected behaviors undergo elaboration that links them to more behaviors in memory relative to expected behaviors, which receive little or no elaboration. This model predicts better memory for unexpected behaviors than for expected behaviors because the former are thought to have more associative links than the latter. We predict that if the processes postulated by these theories affect source memory, source memory will be better for somewhat unexpected than expected items if schemas are activated at encoding.

Different kinds of measures are needed to address our hypotheses. First, in order to test the performance hypothesis, an empirical performance measure of source 
identification is needed that reflects both source memory and guessing. People should perform better on this measure when the information a source presents is expected as opposed to unexpected or neutral. Second, in order to provide evidence that guessing plays a role in this performance advantage, a measure of guessing is needed that is independent of memory processes. According to our guessing hypothesis, the probability of guessing that an item was presented by a source for which it is expected should be above chance level. Third, a pure measure of source memory uncontaminated by guessing is needed to test whether source memory for somewhat unexpected items is better than source memory for expected items.

To investigate the roles of memory and guessing processes, we used formally derived measures of cognitive processes that are based on a multinomial processing tree model of source monitoring (Bayen, Murnane, \& Erdfelder, 1996). The formal model allows us to separate memory processes from guessing processes in sourcemonitoring tasks. With the multinomial model, we can investigate the degree to which the predicted performance advantage in source identification for items that are expected for their source is due to schema-based guessing. We can also investigate whether in addition to guessing, memory plays a role in the influence of schemas on source monitoring for expected and somewhat unexpected information.

We investigated these research objectives in two experiments that used different domains of schematic knowledge and different sets of experimental materials. Experiment 1 used schematic knowledge about scenes, whereas Experiment 2 used schematic knowledge about professional groups.

\section{EXPERIMENT 1}

This experiment investigated whether and how people rely on their schematic knowledge about scenes when making source judgments. In this experiment, participants were presented with object names, each of which was paired with one of two scene labels, either "bedroom" or "bathroom." Each object name presented with a scene label was (according to our norm data) expected for one of the scenes and somewhat unexpected for the other scene. There were two types of objects. Expected bedroom objects were expected for bedroom and somewhat unexpected for bathroom. Expected bathroom objects were expected for bathroom and somewhat unexpected for bedroom. For example, "nightstand" is expected for bedroom and somewhat unexpected for bathroom, whereas "towel" is expected for bathroom and somewhat unexpected for bedroom. We avoided objects that were expected for one scene and highly unexpected for the other scene (e.g., "toilet" for bathroom and bedroom, respectively). A given object was presented with the scene label "bedroom" for some participants and the scene label "bathroom" for other participants. In a later source-monitoring test, participants decided whether presented and nonpresented object names had appeared with bedroom, with bathroom, or with neither. According to the performance hypothesis, a scene is more likely to be correctly identified as the source of an object when the object is expected in that scene than when the object is somewhat unexpected in the other scene. More specifically, the scene bedroom is more likely to be correctly identified than the scene bathroom when expected bedroom objects are presented in both scenes. Conversely, the scene bathroom is more likely to be correctly identified than the scene bedroom when expected bathroom objects are presented in both scenes. Our guessing hypothesis posits that schema-based guessing plays a major role in the higher incidence of correct source identifications for scenes with expected objects. Schemabased guessing is expected to occur when participants do not remember which scene label an object name appeared with. They should guess with higher-than-chance probability that the object appeared with the scene for which it is expected. The attention hypothesis, the schemacopy-plus-tag model, and the associative model predict better source memory for somewhat unexpected objects than for expected objects.

\section{Method}

Participants. Sixty-six adults participated in this experiment. Fifty-eight of them were female, 7 were male, and 1 did not indicate his/her gender on the questionnaire. The participants were between the ages of 18 and 23 years ( $M=19.0$ years) and were recruited from introductory psychology courses at the University of North Carolina at Chapel Hill. They received class credit as a compensation for their participation in the experiment. All participants were native speakers of English. We replaced 1 participant who used only two out of three response options in the memory test, suggesting that this participant did not understand the test instructions.

Design. The design was a $2 \times 2$ factorial with object expectancy (expected bedroom vs. expected bathroom) and source (bedroom vs. bathroom) as independent variables. Both were within-participant variables.

Materials. The items in this experiment were 36 object names (see Appendix A). Eighteen of them represent objects that are expected in a bedroom scene and somewhat unexpected in a bathroom scene. The other 18 object names represent objects that are expected in a bathroom scene and somewhat unexpected in a bedroom scene.

To determine the expectancy of the objects in scenes, we conducted a norming study. This study had two phases: a generation phase and an expectancy-rating phase. Forty-four adults participated in the generation phase of the norming study. These participants were recruited from introductory psychology courses at the University of Memphis and received course credit for their participation. Participants were given a booklet that contained the names of six scenes: bedroom, bathroom, kitchen, office, living room, and child's room. A scene name appeared at the top of each page in the booklet. Participants were instructed to list objects that are likely to be in the named scene. They had 4 min to complete this task for each scene. The order of the scenes was randomized by participant. We then counted how frequently each object had been mentioned over all participants.

Sixty adults participated in the expectancy-rating phase of the norming study. They were from the same pool of participants from which the participants for the generation phase had been drawn. 
However, none of the participants in the generation phase of the study also participated in the expectancy-rating phase. None of the participants in either part of the norming study participated later in the memory experiment.

Participants were given a booklet that contained the same scenes used in the generation phase of the norming study except that the child's room was excluded due to a large degree of overlap with the bedroom. A scene name appeared at the top of each page with a list of randomly ordered object names. The objects were the same for each scene. For the object list, we selected those 114 objects that for any scene had been generated by at least one fourth (i.e., 11) of the participants in the generation phase. Each participant rated the expectancy of each of the 114 objects in each of the five scenes on a 5-point Likert scale $(1=$ very unexpected, $2=$ somewhat unexpected, $3=$ neither unexpected nor expected, $4=$ somewhat expected, $5=$ very expected). The order of scences was randomized by participant.

We obtained average expectancy ratings for each object in each scene. We then selected scenes and objects for our memory experiment on the basis of these expectancy ratings. The goal was to select those two scenes for which the highest number of objects can be found that are expected in one scene and somewhat unexpected in the other scene. The two chosen scenes were bedroom and bathroom. The chosen objects are listed in Appendix A. One group of objects has high mean expectancy ratings for bedroom and low mean expectancy ratings for bathroom. The other group of objects has high expectancy ratings for bathroom and low expectancy ratings for bedroom. Expected items had a mean expectancy rating of at least 4.00. Somewhat unexpected items had a mean rating between 1.22 and 3.10. The mean expectancy ratings for the group of expectedbedroom items were 4.46 for bedroom and 2.03 for bathroom. The mean expectancy ratings for the group of expected-bathroom items were 4.75 for the bathroom and 1.91 for the bedroom. In order to test whether the expectancy of the items was, in fact, different for the two scenes, we conducted $t$ tests on the mean expectancy ratings. Within each item group (expected bedroom/somewhat unexpected bathroom; expected bathroom/somewhat unexpected bedroom), the expectancy ratings for the two scenes differed significantly $(p<.01)$.

Procedure. Each experimental session included between 1 and 4 participants. After signing a consent form, participants were directed to individual computer booths. They read the following cover story and instructions on the computer screen:

Imagine the following scenario. You are spending a day at your friends' summer house off the coast of Florida. Suddenly, there is a hurricane warning. A hurricane has shifted direction and is very likely to hit the summer house. The whole house might be destroyed and washed away by high waves. You have to evacuate immediately and cannot take anything along. Fortunately, your friends have good insurance that will replace everything they might lose in the storm. But they will need a witness who can later tell the insurance company exactly what was in the house. Before you leave the house you have just enough time to look at everything in the bedroom and bathroom.

We will show you a list of names of objects you see in your friends' bedroom and bathroom. These objects will be typed in CAPITAL LETTERS on the right side of the screen. Try your best to remember these object names because we will later show you an insurance list of object names on which you will check off which objects were definitely in the house. If you have any questions please ask the experimenter now.

Participants were not informed of the upcoming source-monitoring test. After reading the cover story, participants were presented with scene-object pairs of the form "bedroom TOWEL." The scene label and the object name were presented one at a time in 24-point size font in the center of the computer screen, with the scene label printed in lowercase letters to the left of the object name, which was printed in capital letters. Scene label and object name appeared in white letters on blue background. Four scene-object pairs served as a primacy buffer and preceded the study list of 24 scene-object pairs. A recency buffer of five scene-object pairs followed.
Twelve of the 24 objects on the study list were expected-bedroom objects; the other 12 were expected-bathroom objects. For purposes of counterbalancing, we randomly divided all expected-bedroom items as well as all expected-bathroom items into three groups-1, 2, and 3 (Appendix A). The assignment of item groups to sources was counterbalanced according to the following scheme. One third of the participants were presented with the items from Group 1 with the bedroom label, and with items from Group 2 with the bathroom label. One third of the participants were presented with the items from Group 3 with the bedroom label and items from Group 1 with the bathroom label. One third of the participants were presented with the items from Group 2 with the bedroom label and items from Group 3 with the bathroom label.

The presentation order of the scene-object pairs was randomized by participant. Thus, expected-bathroom items and expected-bedroom items were randomly intermixed, as were the two scenes. Presentation time for each scene-object pair was $4.5 \mathrm{sec}$.

Immediately after presentation of the study list, participants received instructions for a source-monitoring test. In this test, participants were presented with 24 target object names they had seen before, randomly intermixed with 12 distractor object names. The distractor items consisted of the objects in the object group $(1,2$, or 3; Appendix A) that had not been presented to the respective participant. For example, if a participant saw the objects from Groups 1 and 2 during study, then the Group 3 objects served as distractor items. Thus, for objects from each one of the object groups $(1,2$, and 3 ), "bedroom" was the correct answer for one third of the participants, "bathroom" was the correct answer for one third, and "neither" was the correct answer for one third.

The test item was printed in all capital letters in 24-point size font. Above the test item appeared the question, "Which room was this object presented with?" Both this question and the item appeared in white letters on black background. Participants gave their responses by hitting color-coded keys on the computer keyboard. The keys " $D$ " and "K" were marked with green and yellow stickers, respectively, and were used to indicate the two scenes. The space bar was marked with a red sticker and indicated "neither." The words "bedroom," "bathroom," and "neither" appeared on the lower half of the computer screen above the corresponding response keys and in corresponding colors. The assignment of the " $K$ " and " $D$ " response keys to "bedroom" and "bathroom" was completely counterbalanced across participants. Responses were self-paced. Participants were told that they could take as much time for each response as they wished. Six practice items preceded the 36 test items. After completing the memory test, participants indicated their age and gender on a questionnaire and were debriefed.

\section{Results}

The raw data for a source-monitoring paradigm like the one used in our experiment can be presented in the form of a $3 \times 3$ table in which the rows represent the sources (bedroom, bathroom, new) and the columns represent participant responses ("bedroom," "bathroom," "neither"). The raw data for Experiment 1 are presented in Appendix B.

Every participant response in a source-monitoring task like the one used in our experiment is influenced by item recognition (i.e., remembering whether the item is old or new), by source memory (i.e., remembering the source of the item), and by response or guessing biases. Various measures have been suggested in the literature to measure different components of the source-monitoring task (for a review, see Murnane \& Bayen, 1996). For our data analyses, we need (1) a performance measure of source 


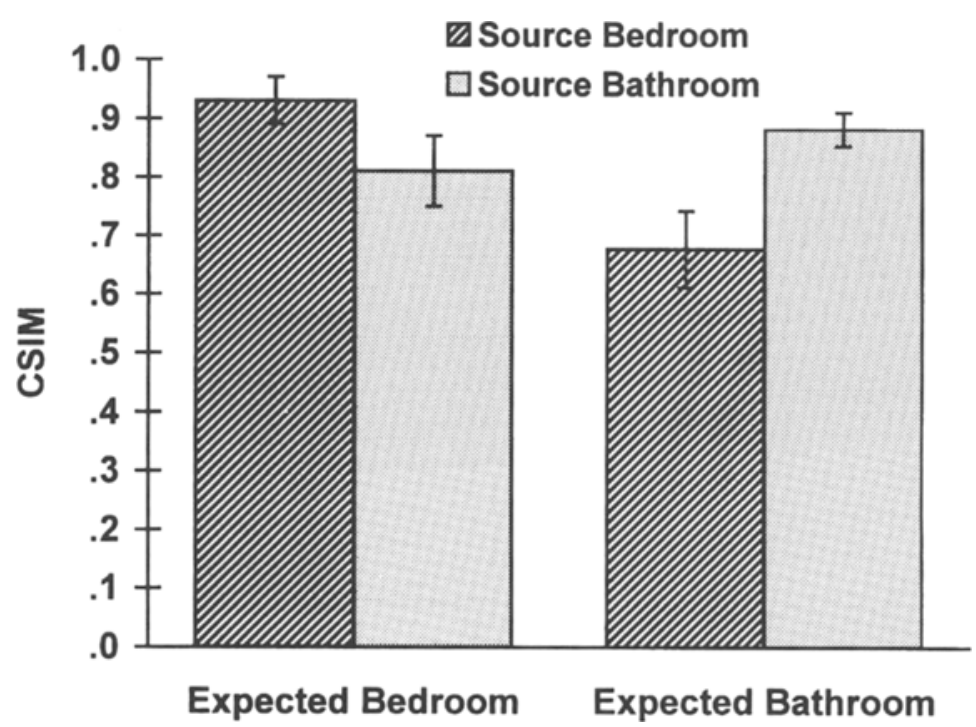
Figure 1. Conditional source identification measure (CSIM) for objects as a
function of expectancy and source, Experiment 1. Error bars indicate $95 \%$
confidence intervals.

identification that is independent of item recognition, (2) a measure of source guessing that is independent of memory for the source and independent of item recognition, and (3) a measure of memory for the source that is independent of source guessing and item recognition. We will first present analyses with an empirical source identification measure as the dependent variable, and then analyses with formal-model based source-memory and guessing measures as dependent variables. We used the conventional level of alpha $=.05$ for all statistical analyses reported in this article unless otherwise noted.

As an empirical performance measure, we chose the single-source conditional source identification measure (CSIM) because it is independent of item recognition under most circumstances (Murnane \& Bayen, 1996). The single-source CSIMs for Sources A and B, respectively, are calculated as follows:

$$
\begin{aligned}
& \operatorname{CSIM}_{\mathrm{A}}=Y_{\mathrm{AA}} /\left(Y_{\mathrm{AA}}+Y_{\mathrm{AB}}\right), \\
& \operatorname{CSIM}_{\mathrm{B}}=Y_{\mathrm{BB}} /\left(Y_{\mathrm{BB}}+Y_{\mathrm{BA}}\right),
\end{aligned}
$$

where $Y_{i j}$ indicates the frequency of responses of type $j$ to items of type $i$.

Figure 1 presents CSIM as a function of expectancy and source. We performed a repeated measures analysis of variance (ANOVA) with object expectancy (expectedbedroom vs. expected-bathroom) and source (bedroom vs. bathroom) as within-participant independent variables, and single-source CSIM as the dependent variable. The ANOVA yielded a significant main effect of expectancy, with better source identification for expected-bedroom items than for expected-bathroom items $[F(1,65)=27.36$, $\left.M S_{\mathrm{e}}=.02\right]$. There was also a main effect of source, with better source identification for bathroom than for bed- room $\left[F(1,65)=5.18, M S_{\mathrm{e}}=.02\right]$. More importantly, there was a significant interaction of expectancy and source $\left[F(1,65)=31.39, M S_{\mathrm{e}}=.06\right]$. Simple main effects analyses were performed on the interaction. CSIM for expectedbedroom items was significantly higher when bedroom was the source $(M=.93)$ as opposed to bathroom $[M=.81$; $\left.F(1,65)=8.33, M S_{\mathrm{e}}=.06\right]$. Also, CSIM for expectedbathroom items was significantly higher when bathroom was the source $(M=.88)$ as opposed to bedroom $[M=.68$; $\left.F(1,65)=22.83, M S_{\mathrm{e}}=.06\right]$. The expectancy $\times$ source interaction supports the performance hypothesis, which proposes that the likelihood of correct source identification is higher when an item-source pairing is expected than when it is somewhat unexpected.

Although CSIM is an adequate measure of participants' performance in the task, it does not allow conclusions regarding the cognitive processes that led to this performance. CSIM is a performance measure of source identification that is a conglomerate of source-memory processes and guessing biases. For example, when a participant makes a correct source attribution regarding an object item that had been presented with bedroom, this correct source judgment might occur because the participant actually remembers that bedroom was the source of the item, or because the participant guesses that bedroom was the source of the item. In order to disentangle the contributions of source memory and guessing to source identification, we used a multinomial processing tree model of source monitoring.

Multinomial processing tree models are a class of formal models that assume that there are discrete cognitive states (such as item recognition and source discrimination) that are attained with certain probabilities. These probabilities cannot be observed directly, but they can be 


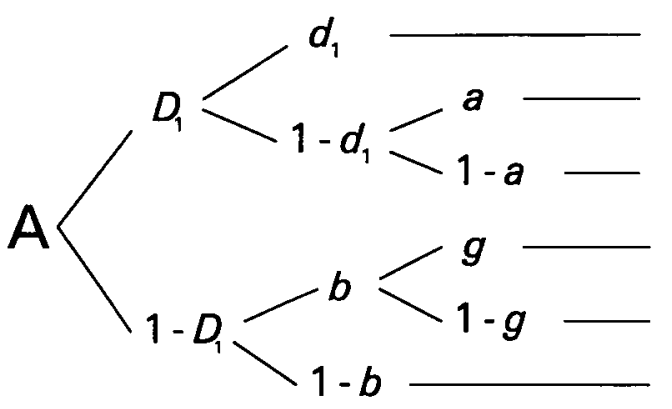

"A"

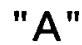

"B"

"A"

"B"

"N"
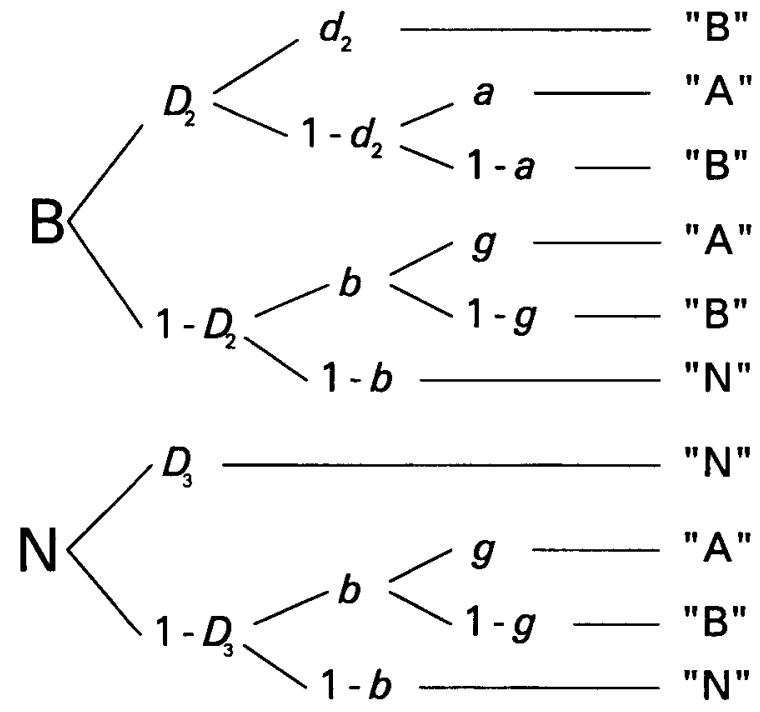

Figure 2. Two-high-threshold multinomial model of source monitoring: $D_{1}=$ probability of recognizing an item that had been presented by Source $A ; D_{2}=$ probability of recognizing an item that had been presented by Source $B ; D_{3}=$ probability of knowing a distractor item is new; $d_{1}=$ probability of correctly remembering the source of an item that had been presented by Source $A ; d_{2}=$ probability of correctly remembering the source of an item that had been presented by Source $B ; a=$ probability of guessing that a recognized item had been presented by Source $A ; b=$ probability of guessing that an unrecognized item is old; $g=$ probability of guessing that an unrecognized item had been presented by Source $A$. Reprinted from "Source Discrimination, Item Detection, and Multinomial Models of Source Monitoring" by U. J. Bayen, K. Murnane, and E. Erdfelder, 1996, Journal of Experimental Psychology: Learning, Memory, and Cognition, 22, p. 202. Copyright 1996 by the American Psychological Association. Reprinted with permission.

mapped onto frequencies of observable events such as responses in a source-monitoring task. Model parameters representing probabilities of attaining cognitive states are derived from empirical data by way of maximumlikelihood parameter estimation. For a detailed statistical analysis of multinomial processing tree models, see $\mathrm{Hu}$ and Batchelder (1994) or Riefer and Batchelder (1988). Multinomial models have been used with increasing frequency in recent years and are available for a wide variety of cognitive tasks (e.g., Batchelder \& Riefer, 1980; Ben- der, Wallsten, \& Ornstein, 1996; Erdfelder \& Buchner, 1998; Schweickert, 1993).

Batchelder and Riefer (1990) were the first to apply this model-based approach to source monitoring. The objective of multinomial models of source monitoring is to permit the separate estimation of source-memory parameters, item-memory parameters, and guessing parameters from data collected in a source-monitoring task like the one employed in the present research. Batchelder and Riefer's (1990) original multinomial model of source monitoring was criticized by Kinchla (1994) because it includes a one-high-threshold (1HT) model of item recognition. This model is known to be an inadequate model for simple old-new item recognition tasks because it fits ROC data poorly (see, e.g., Kintsch, 1970). In response to this criticism, alternative multinomial models of source monitoring were developed (Batchelder, Hu, \& Riefer, 1994; Batchelder, Riefer, \& Hu, 1994; Bayen et al., 1996) and evaluated. Bayen et al. found in an empirical evaluation that a source-monitoring model that is based on a two-high-threshold (2HT) model of item recognition is superior to all alternative models of source monitoring because it is the only available model that provides valid and independent measures of both old-new item recognition and source memory. In contrast to the 1HT model, the 2HT model assumes that some distractor items that had not appeared during study can be recognized as new. The $2 \mathrm{HT}$ model of simple item recognition on which the $2 \mathrm{HT}$ model of source monitoring is based presents an adequate fit to ROC data (Snodgrass \& Corwin, 1988). For these reasons of superiority over alternative models we used the $2 \mathrm{HT}$ model of source monitoring for our analyses.

This model has the distinct advantage of providing unconfounded, pure measures of item recognition, source memory, and guessing biases if the assumptions underlying the model are valid. The validity of the assumptions can be empirically tested via goodness-of-fit tests that assess how well the model fits the empirical data.

Figure 2 shows the 2HT multinomial model of source monitoring. We will first explain the model, then present our model-based analyses of the data from Experiment 1. Refer to the first processing tree in Figure 2. This tree represents a test trial in which a participant is tested with an item that had previously been presented by Source A. The participant will recognize this item as a target item with probability $D_{1}$. With probability $d_{1}$ the participant remembers that this item is a Source-A item. With the complementary probability $1-d_{1}$ the participant does not remember that this item originated from Source A and must therefore guess the source of the item. With probability $a$ the participant will guess that this item was presented by Source A. With the complementary probability $1-a$ the participant guesses that it was presented by Source B. Note that the model assumes that the participant either does or does not accurately remember the source, and, if not, guesses. According to this model, the participant does not ever inaccurately "remember" the source. If an item is not recognized as a target item (with probability $1-D_{1}$ ), 


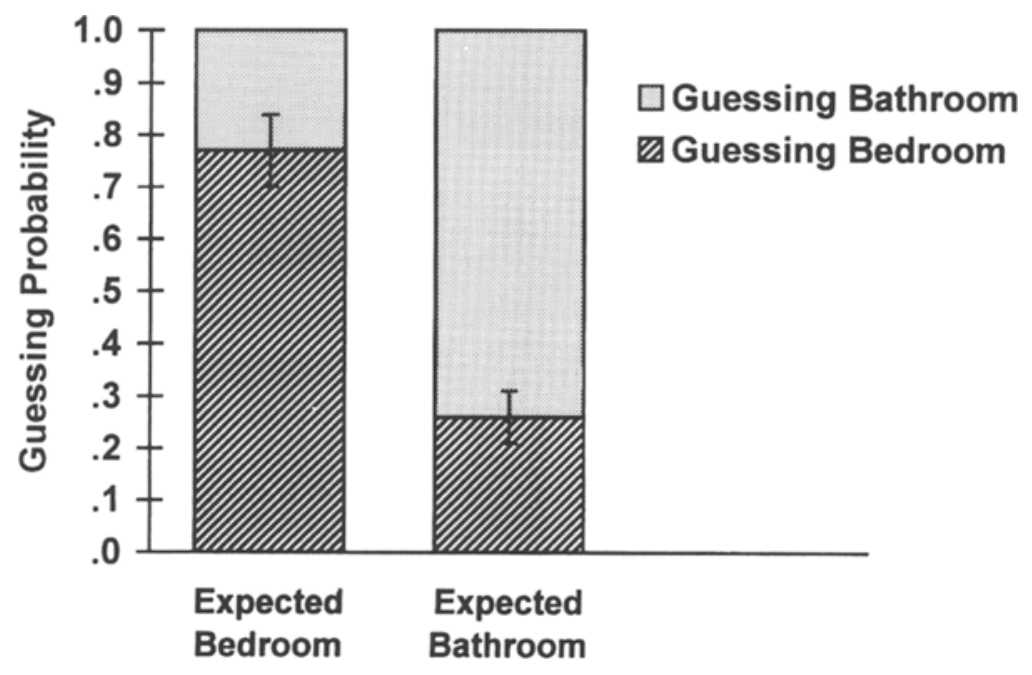

Figure 3. Guessing probability as a function of expectancy of objects, Experiment 1 . Error bars indicate $95 \%$ confidence intervals.

the participant will, with probability $b$, guess that it is a target item. With probability $g$ he/she will guess that this item originated from Source A. With probability $1-g$, the participant guesses that this item originated from Source B. With probability $1-b$, the participant guesses that an unrecognized item is a distractor item. The probability of a particular response ("A," "B," or "N") to items originating from Source $\mathrm{A}$ is calculated by summing the probabilities from all branches leading to that responsefor example,

$p($ "A" $\mathrm{A})=D_{1} * d_{1}+D_{1} *\left(1-d_{1}\right) * a+\left(1-D_{1}\right) * b * g$.

The corresponding probabilities hold for items that were presented by Source B during study (refer to the second processing tree in Figure 2). Index 2 denotes itemrecognition and source-memory parameters for Source-B items. The third processing tree in Figure 2 illustrates the processes involved in making judgments about distractor items. With probability $D_{3}$, participants know that a distractor item is new, with probability $1-D_{3}$ they do not. It is this possibility to recognize new items as new that distinguishes the $2 \mathrm{HT}$ model from the $1 \mathrm{HT}$ model originally proposed by Batchelder and Riefer (1990). If the participant does not recognize the new item, guessing processes set in that are equivalent to the guessing processes for unrecognized old items. That is, participants have to guess whether the item is old or new (probabilities $b$ and $1-b$, respectively) and, if they guess old, they have to guess from which source it originated (probabilities $g$ and $1-g$, respectively).

The model as depicted in Figure 2 is not mathematically identifiable because it has eight free parameters, while there are only $6 d f$ in the data. Bayen et al. (1996, p. 202) have listed all identifiable submodels of this model. These submodels are constructed by imposing equality constraints on parameters. For example, a submodel may in- clude the assumption that source memory for the two sources is equal $\left(d_{1}=d_{2}\right)$ or that source guessing probabilities are equal for recognized and unrecognized items $(a=g)$. The goodness-of-fit of submodels to empirical data is evaluated with the log-likelihood ratio statistic, $G^{2}$, which is asymptotically chi-square distributed (Hu \& Batchelder, 1994). If a submodel offers a good fit to the data as indicated by $G^{2}$, the assumptions underlying this model are valid. Different submodels can be tested against each other by comparing model fits.

We used the 2HT multinomial model to analyze the raw data presented in Appendix B. We arbitrarily designated bedroom as Source A and bathroom as Source B. We performed all parameter estimations, goodness-offit tests, and significance tests with a computer program by $\mathrm{Hu}$ (1991).

The first step in multinomial analyses is to determine which submodel to use. As a starting point, we fitted Submodel 4 (according to the nomenclature used by Bayen et al., 1996, Figure 4) of the 2HT multinomial model. This submodel (Bayen et al., 1996) has four free model parameters and is the most parsimonious submodel of the 2HT model depicted in Figure 2. In addition to the general assumptions of the $2 \mathrm{HT}$ model as stated above, Model 4 makes the following assumptions: (1) Item recognition is equal for items that were presented with bedroom, items that were presented with bathroom, and new items $\left(D_{1}=D_{2}=D_{3}\right)$; (2) source memory is equal for items that were presented with bedroom and for items that were presented with bathroom $\left(d_{1}=d_{2}\right)$; (3) the probability of guessing "bedroom" or "bathroom" is equal for recognized and unrecognized items $(a=g)$. The four parameters of Model 4 are thus as follows: parameter $D$, which measures item recognition; parameter $d$, which measures source memory; parameter $b$, which measures the probability of guessing that an object is old; and pa- 


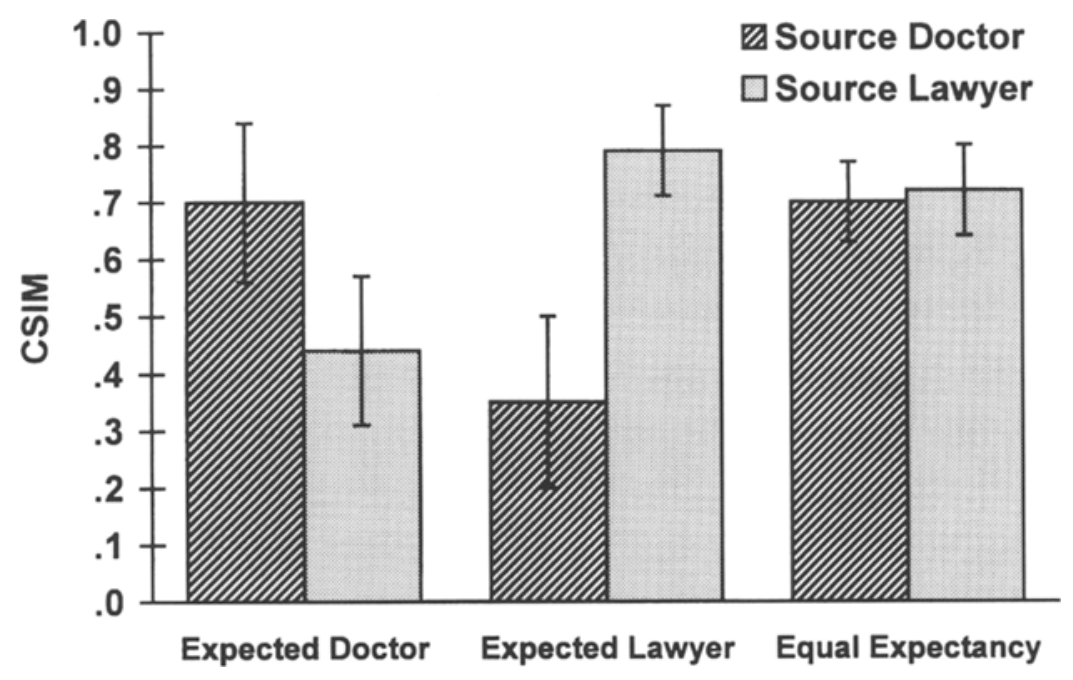

Figure 4. Conditional source identification measure (CSIM) for sentences as a function of expectancy and source, Experiment 2 . Error bars indicate $95 \%$ confidence intervals.

rameter $g(=a)$, which measures the probability of guessing that an object was presented with bedroom. All parameter values, confidence intervals, and goodness-of-fit indices for this model are reported in Table 1. As the goodness-of-fit indices show, Model 4 fit the data from both expectancy conditions of our experiment. This good fit indicates that the assumptions of Model 4 as listed above are valid for our data. Contrary to one of the assumptions of Model 4, the attention hypothesis, the schema-copy-plus-tag model, and the associative model predict that source memory for somewhat unexpected items should be better than source memory for expected items. This prediction can be tested by comparing the goodness-of-fit of Model 4 against that of Model 5d (see Bayen et al., 1996, Figure 4). Model 5d makes the same assumptions as Model 4 except that it releases the restriction $d_{1}=d_{2}$. Comparisons of the goodness-of-fit for both models showed that for both conditions of the design, the release of the restriction $d_{1}=d_{2}$ did not lead to a statistically significant increase in model fit $\left[G^{2}(1)=3.25\right.$ and $G^{2}(1)=0.25$ for bedroom items and bathroom items, respectively], indicating that source memory does not differ significantly between the two sources. Parameter estimates of Model $5 \mathrm{~d}$ show an effect in the direction predicted by the attention hypothesis, the schema-copy-plus-tag model, and the associative model (i.e., the source-memory parameter is higher for the somewhat unexpected relative to the expected source), but this effect is not statistically significant.

Because goodness-of-fit tests indicated that Model 4 is the model that most adequately accounts for our data, we chose this model as the basis for the following analyses comparing guessing parameters between expectedbedroom and expected-bathroom items. Another parameter of particular interest for our study is the guessing parameter $g$, which indicates the probability of guessing "bedroom." The complementary probability $1-g$ is the probability of guessing "bathroom." Note that these probabilities are conditional probabilities that are conditional on not remembering the source. In other words, the parameter $g(=a)$ is not affected by the probability with which the source of items is remembered (and vice versa). We predicted that when participants do not remember the source of an object, they will guess with higher-than-chance probability toward the source that is the more expected one based on schematic knowledge about the sources. Parameter $g$ should thus be significantly above the chance level of .5 for expected-bedroom items, and significantly below .5 for expected-bathroom items. Figure 3 presents the guessing probabilities for the two types of items.

We tested whether the guessing probability $g$ differed significantly across conditions (see Bayen et al., 1996, on how to perform between-cells significance tests within the multinomial modeling framework). Parameter $g$ (guessing bedroom) is significantly higher than .5 for objects that are expected for bedroom $\left[G^{2}(1)=51.73\right]$ and significantly lower than .5 for objects that are expected for bathroom $\left[G^{2}(1)=67.49\right]$. The model-based results thus indicate that when participants do not remember where the object name appeared, they guess with higher-than-chance probability that it appeared with the expected scene.

According to the multinomial analyses, item recognition (model parameter $D$ ) was not significantly different for expected-bedroom and expected-bathroom items. There was significantly better source memory (model parameter $d$ ) for expected-bedroom items than for expectedbathroom items $\left[G^{2}(1)=10.82\right]$. These results concur with the finding of a higher CSIM in the expected-bedroom in comparison to the expected-bathroom condition. As noted, 
Table 1

Parameter Estimates, Confidence Intervals, and $G^{2}$ Goodness-of-Fit Values for the Four-Parameter Two-High Threshold Multinomial Model of Source Monitoring for the Two Conditions of Expectancy in Experiment 1

\begin{tabular}{lccccc}
\hline Expectancy & $D$ & $d$ & $g$ & $b$ & $G^{2}(2)$ \\
\hline Bedroom & $.78(.75-.81)$ & $.89(.83-.95)$ & $.77(.71-.83)$ & $.62(.55-.68)$ & 4.05 \\
Bathroom & $.75(.71-.78)$ & $.71(.64-.78)$ & $.26(.22-.31)$ & $.78(.73-.83)$ & 1.40
\end{tabular}

Note-These are probability estimates that can range from 0 to $1 . D$, item recognition parameter (estimates higher than 0 indicate that some item recognition is present); $d$, source memory parameter (estimates higher than 0 indicate that some source memory is present); $g$, probability of guessing an item was presented with bedroom (estimates higher than the chance level of .5 indicate guessing bias toward bedroom; estimates lower than .5 indicate guessing bias toward bathroom); $b$, probability of guessing an item is old (chance level .5 ). $95 \%$ confidence intervals are in parentheses. $G^{2}(2)$ values lower than 5.99 indicate a good fit of the model to the data.

the good fit of Model 4 for both the expected-bedroom and expected-bathroom conditions implies that source memory was equal for the expected and the somewhat unexpected source $\left(d_{1}=d_{2}\right)$. Thus, the multinomial modeling analyses show that the higher scores in CSIM for expected scene-object pairings are due to schema-based guessing. The evidence for schema-based guessing supports our guessing hypothesis.

\section{EXPERIMENT 2}

Experiment 2 had several purposes. One of them was to replicate the results of Experiment 1 with materials from a different domain of schematic knowledge. The domain chosen for Experiment 2 was professional groups, with a "doctor" and a "lawyer" serving as the sources. The items presented by these sources were statements that varied in rated expectancy. A second purpose of Experiment 2 was to test the guessing hypothesis more completely than it was tested in Experiment 1. According to this hypothesis, schema-based guessing of the source occurs when items are expected for the source that presented them. In addition, the hypothesis states that no guessing bias should occur when participants cannot draw on a schema. In Experiment 1, all items were expected for either one or the other source. Accordingly, we found schema-based guessing in both conditions of the experiment. This experiment did not test whether a guessing bias is absent when no schema is activated. To test this aspect of the guessing hypothesis in Experiment 2, we added "neutral" statements that were equally expected for both sources. We compared the other two types of statements that varied in schema expectedness for the two sources (i.e., expected for one source vs. somewhat unexpected for the other source) with the equally expected statements.

We considered including equally expected statements in the scene paradigm of Experiment 1. However, of those object items from our normed pool that have equal expectancy ratings for bedroom and bathroom, many are highly unexpected in both bedroom and bathroom (such as "microwave"). Inclusion of these items would have led to a confound with the equally (un)expected items re- membered better because of a consistency effect (Pezdek, Whetstone, Reynolds, Askari, \& Dougherty, 1989). The domain of professional groups is one in which items can easily be found that have equal expectancy for two sources and are plausible (i.e., not highly unexpected) for either source.

A further purpose of Experiment 2 was to explore whether source-specific schemas that are activated at the time of retrieval are used in source monitoring. Schemas have been shown to influence performance when they are activated at the time of retrieval of information (Anderson \& Pichert, 1978). In Experiment 2, participants were not informed until after encoding which professional group each source belonged to.

In this experiment, information was presented by two sources that appeared on a computer screen as male faces with the name labels "Tom" and "Jim." During the acquisition phase, both sources presented statements that, according to our norm data, were expected doctor statements (i.e., expected for a doctor and somewhat unexpected for a lawyer), expected lawyer statements (i.e., expected for a lawyer and somewhat unexpected for a doctor), and statements that were equally expected for both. At the time of test, target and distractor statements were presented along with both possible sources; these were labeled "Tom = Doctor" and "Jim = Lawyer." Participants had three response options; they were instructed to attribute a given statement to the doctor, the lawyer, or neither.

We predicted a significant interaction of statement expectancy and source on a performance measure of source identification, which is CSIM. According to the performance hypothesis, participants should be more likely to correctly identify the source of statements that are expected for a source relative to responses somewhat unexpected for a source. In addition, the correct source identification of the equally expected statements should not differ between the two sources, because the expectancy level of the statements is equivalent.

We also investigated the degree to which source identification is based on guessing. According to the guessing hypothesis, when participants do not remember which 


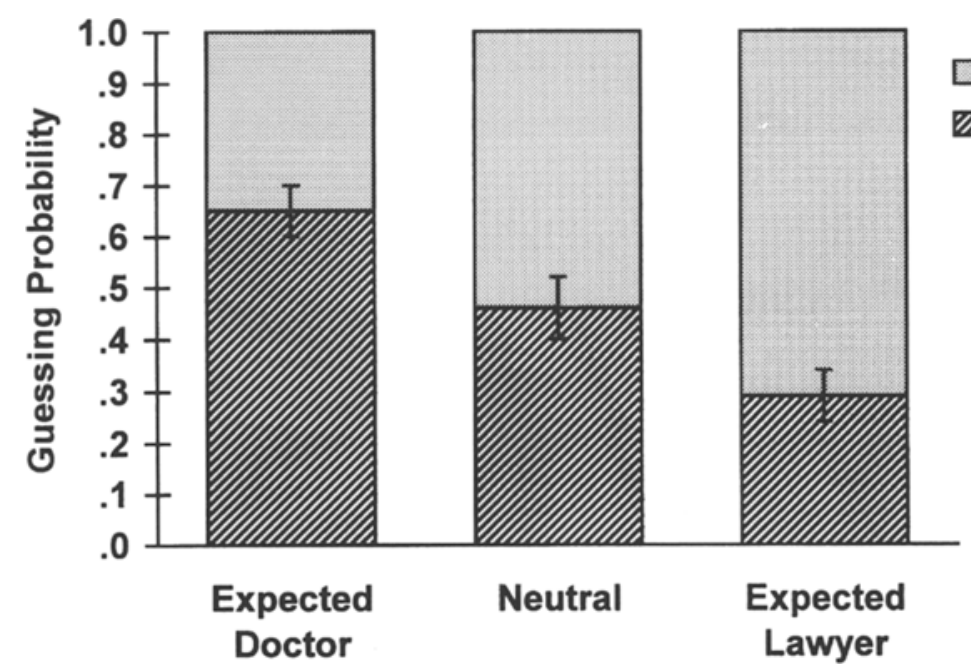

\section{Guessing Lawyer Q Guessing Doctor}

Figure 5. Guessing probability as a function of expectancy of sentences, Experiment 2. Error bars indicate $95 \%$ confidence intervals.

one of the two sources presented a piece of information, they guess in favor of the source from which such information is expected. Such guessing increases the sourceidentification performance for items that are expected for their source. The guessing probability was predicted to be significantly different from chance level for items that are expected for either the doctor or the lawyer source. The hypothesis further states that guessing will be absent when no schema is used. Thus, guessing toward either source was predicted to be at chance level for those statements that are equally expected for both sources, because there is no schema to guide guessing.

\section{Method}

Participants. Twenty-four undergraduate students from the University of North Carolina at Chapel Hill participated in this experiment. They were recruited from introductory psychology classes and received course credit for their participation. Eleven of the participants were male, and 13 were female. Mean age was 20.1 years $(S D=1.89)$. All participants were native speakers of English. Because of a technical error during the data collection, 1 participant had to be replaced.

Design. The design was a $3 \times 2$ factorial with expectancy of statements (expected-doctor statements, expected-lawyer statements, equally expected statements) and source of statements (doctor vs. lawyer) as within-participant independent variables.

Materials. Appendix C lists all statements used in this experiment. To develop this list we constructed a pool of 327 sentence statements that were, according to our intuitions, highly expected for doctors, highly expected for lawyers, or of similar expectancy for both professional groups. For each sentence, there was at least one other similar sentence in the pool. The purpose of including similar sentences was to find target and distractor items for our memory test. The similar sentences differed in one word or phrase so that the meaning of the statement changed (e.g., "Don't drink alcohol with this" and "Don't drink caffeine with this"). We tested our intuitions regarding the expectancy of these statements in a norming study in which we asked college students to rate the expectancy of each sentence for each of the two professions.
Forty-five undergraduate students from the University of Memphis participated in the norming study and received course credit for their participation. Half the participants of the norming study rated the expectancy of all 327 sentences for doctor first, then for lawyer; the other half rated the expectancy of the sentences for the professional groups in opposite order. Sentences were presented in different random order for the doctor and the lawyer ratings, respectively. Participants received instructions to "indicate how expected (or likely) it would be for a member of the profession to make that statement." They gave their responses on a 5-point Likert scale ( $1=$ very unexpected, $2=$ somewhat unexpected, $3=$ neither unexpected nor expected, $4=$ somewhat expected, and $5=$ very expected).

We calculated average expectancy ratings for each sentence separately for the two professional groups. From the pool of 327 sentences we chose 96 sentence pairs that included two similar sentences. Of the 96 pairs, 32 are expected-doctor pairs, 32 expected-lawyer pairs, and 32 equal-expectancy pairs. In our source-monitoring tests, one member of each sentence pair would serve as a target item, and the other member of the pair would serve as a distractor item (see Procedures section). See Appendix C for a complete listing of the selected sentence items. Target sentences are listed in the left column; distractor sentences are listed in the right column. The decision whether a sentence would serve as a target or distractor item was made at random.

The high-expectancy doctor statements had a mean expectancy rating of at least 4.16 for doctor ( $M=4.69$ across all sentences) and a mean expectancy rating of at most 2.09 for lawyer $(M=1.42$ across all sentences). The high-expectancy lawyer statements had a mean expectancy rating of at least 4.24 for lawyer $(M=4.76$ across all sentences) and a mean expectancy rating of at most 2.16 for doctor $(M=1.36$ across all sentences). According to $t$ tests, the mean doctor ratings and the mean lawyer ratings were significantly different within these two conditions. The equally expected statements had mean ratings between 2.24 and 4.40 for both doctor and lawyer. The mean doctor rating and the mean lawyer rating did not differ more than .57 for any of these sentences. Across all equally expected sentences, the mean ratings were 2.92 for doctor and 2.94 for lawyer, a nonsignificant difference.

Two faces presented on the computer screen served as sources of information in the experiment. They were black-and-white faces of middle-aged males that had been constructed using a computerized 
Identikit. These faces have been used in prior source-monitoring studies by Bayen and Murnane (1996, Figure 1, "Jack" and "John") as well as Bayen et al. (1996, Figure 5, "Jack" and "John").

Procedure. Each experimental session included between 2 and 5 participants who signed consent forms and were seated in individual computer booths. Participants were presented with 96 statements by two different sources. Participants were informed that they would see pictures of two people, Tom and Jim, accompanied by sentences that Tom or Jim say. They were instructed to read the sentences carefully and remember them as best as they could, because they would later be asked to remember those sentences. Participants were not informed of the upcoming source-monitoring test. Six practice items were presented first. Participants were then presented with the study list of 96 sentences (see left column of Appendix C). The sentences from each of the three conditions (expected doctor, expected lawyer, equal expectancy) were randomly divided into two groups. One group was presented by the source "Tom" and the other one by the source "Jim." Sentences were presented one at a time centered at the bottom of the computer screen in single quotes. Above the sentence appeared the picture of the source in the middle of the screen. Below the picture, centered on the screen, appeared the name of the source in capital letters (i.e. TOM or JIM) followed by a colon to indicate that the statement was spoken by the source. The font size of the sentences was 24-point and that of the source labels 45-point. The order of sentences was randomized by participant, and sources alternated randomly in their presentation of sentences. Each sentence appeared for $6 \mathrm{sec}$ and was immediately followed by the next sentence.

Immediately after presentation of the study list, instructions for the source-monitoring test appeared on the computer screen. Participants were told that it might be helpful for them to know that Tom was a doctor and Jim was a lawyer. They were further informed that they would now see statements at the top of the computer screen, and they were asked to indicate whether a statement had been presented by Tom, the doctor, had been presented by Jim, the lawyer, or had been presented by neither of them. During the source-monitoring test, both source pictures appeared side-by-side on the screen. Below the source pictures appeared profession labels along with the source names in capital letters: TOM $=$ DOCTOR and $\mathrm{JIM}=$ LAWYER. Below these labels appeared the third response option, NEITHER, centered on the screen.

Ninety-six test sentences appeared one at a time centered at the top of the computer screen. Throughout the test, the words "Who said:" appeared on the upper left portion of the computer screen above the test sentences. The order of test sentence presentation was randomized by participant. Forty-eight of the 96 test sentences were target items that had been presented during study. Of these target test sentences, 16 were expected-doctor sentences, 16 were expectedlawyer sentences, and 16 were equal-expectancy sentences. Of each group of 16 items, 8 had been presented by Tom, the doctor, and 8 by Jim, the lawyer. The other half of the test sentences were distractor items that were similar to the 48 studied sentences that did not appear in the test. Of the 48 distractor sentences, 16 were expected-doctor, 16 expected lawyer, and 16 equally expected for both professional groups.

Two versions of the memory test were constructed. In Version A, test items were Target Items 1-16 (Appendix C) of each of the three item groups and Distractor Items 17-32. In Version B, test items were Target Items 17-32 and Distractor Items 1-16. The two test versions were counterbalanced across participants.

Participants gave a response by pushing one of three color-coded keys on the computer keyboard. The keys " $D$ " and " $K$ " were marked with green and yellow color stickers, respectively, and were used to indicate the two sources. The assignment of these two computer keys to the two sources was completely counterbalanced across participants. That is, for half of the participants, the green sticker indicated "doctor" and the yellow sticker "lawyer." For the other half of the participants, the assignment of keys to sources was reversed. This counterbalancing variable was completely crossed with the test-versions counterbalancing variable. The space bar was marked with a red color sticker and indicated the "neither" response for all participants. Each response key was directly below and marked in the same color as the corresponding response option on the computer screen. Participants responded at their own pace. After a participant had given a response, the next test sentence appeared on the screen. Error feedback was not provided. The 96 test sentences were preceded by six practice sentences. After completion of the memory test, participants received a brief demographics questionnaire and were debriefed as to the purpose of the study.

\section{Results}

The raw data from this experiment are presented in Appendix D. CSIMs for the different conditions of the experiment are depicted in Figure 4. We performed a repeated measures ANOVA on CSIM with the two withinparticipant factors expectancy of statement (expecteddoctor statements, expected-lawyer statements, and equally expected statements) and source (doctor vs. lawyer). The ANOVA yielded a significant main effect of expectancy $\left[F(2,46)=5.68, M S_{\mathrm{e}}=.05\right]$. CSIM was higher for statements that were equally expected for both sources than for statements that were either expected for the doctor or expected for the lawyer. The main effect of source was marginally nonsignificant $[F(1,23)=3.83$, $\left.M S_{\mathrm{e}}=.04, p<.06\right]$, with a tendency toward higher source identification for items that had been presented by the lawyer. Most importantly, the predicted interaction between expectancy and source was significant $[F(2,46)=$ $\left.14.49, M S_{\mathrm{e}}=.10\right]$. Simple main effects analyses were performed on the interaction. Correct source identification as measured by CSIM was significantly higher for expected-doctor statements when presented by the doctor $(M=.70)$ as opposed to the lawyer $[M=.44 ; F(1,23)=$ $\left.8.20, M S_{\mathrm{e}}=.10\right]$. Similarly, correct source identification was significantly higher for expected-lawyer statements when presented by the lawyer $(M=.79)$ as opposed to the doctor $\left[M=.35 ; F(1,23)=23.60, M S_{\mathrm{e}}=.10\right]$. We can conclude from the interaction that source identification is better when the source presents expected information rather than somewhat unexpected information. These results support our performance hypothesis. Source identification for equally expected statements was not significantly different for the doctor source $(M=.70)$ and the lawyer source $(M=.72)$.

An interesting pattern of results emerged when we compared the equally expected statements with the other two types of statements. For this comparison, we calculated the average conditional source identification measure (ACSIM; Murnane \& Bayen, 1996) for equally expected statements (i.e., the mean of CSIM for equally expected items that had been presented by the doctor and CSIM for equally expected items that had been presented by the lawyer), ACSIM for expected statements (i.e., the 
Table 2

Parameter Estimates, Confidence Intervals, and $G^{\mathbf{2}}$ Goodness-of-Fit Values for the Four-Parameter Two-High Threshold Multinomial Model of Source Monitoring for the Three Conditions of Expectancy in Experiment 2

\begin{tabular}{lccccc}
\hline \multicolumn{1}{c}{ Expectancy } & $D$ & $d$ & $g$ & $b$ & $G^{2}(2)$ \\
\hline Expected Doctor & $.34(.28-.39)$ & $.39(.18-.60)$ & $.65(.61-.69)$ & $.63(.59-.67)$ & 0.25 \\
Expected Lawyer & $.28(.22-.33)$ & $.26(.03-.49)$ & $.29(.25-.33)$ & $.55(.51-.59)$ & 4.28 \\
Equal Expectancy & $.50(.45-.55)$ & $.65(.51-.79)$ & $.46(.41-.52)$ & $.53(.48-.58)$ & 1.17 \\
\hline
\end{tabular}

Note-These are probability estimates that can range from 0 to $1 . D$, item recognition parameter (estimates higher than 0 indicate that some item recognition is present); $d$, source memory parameter (estimates higher than 0 indicate that some source memory is present); $g$, probability of guessing an item was presented by the doctor (estimates higher than the chance level of .5 indicate guessing bias toward doctor; estimates lower than .5 indicate guessing bias toward lawyer); $b$, probability of guessing an item is old (chance level .5); $95 \%$ confidence intervals are in parentheses. $G^{2}(2)$ values lower than 5.99 indicate a good fit of the model to the data.

mean of CSIM for expected-doctor items that had been presented by the doctor, and CSIM for expected-lawyer items that had been presented by the lawyer), and ACSIM for somewhat unexpected statements (i.e., the mean of CSIM for expected-doctor items that had been presented by the lawyer, and CSIM for expected-lawyer items that had been presented by the doctor). We performed a oneway repeated measures ANOVA on ACSIM across the three types of statements. The effect of expectancy was significant $\left[F(2,46)=16.66, M S_{\mathrm{e}}=.05\right]$. Tukey tests were performed to determine which pairs of means for the statement types were significantly different. ACSIM for the equally expected statements $(M=.71, S D=.16)$ was not significantly different from ACSIM for the expected statements $(M=.75, S D=.19)$. However, ACSIM for the equally expected statements was significantly higher than ACSIM for the somewhat unexpected statements $(M=.40, S D=.27)$. The ACSIM for expected statements was significantly higher than the ACSIM for somewhat unexpected statements. This latter result is consistent with the results from the interaction. Thus, overall, whereas schema disconformity of information and source hurts source identification, schema conformity does not increase source identification relative to a neutral, equalexpectancy condition. The lack of a difference in source identification between expected statements and equally expected statements appears to contradict our performance hypothesis, according to which source identification performance should be better when information is more expected for its source than equally expected for both sources. We will address this issue in the discussion section.

We also performed multinomial model-based analyses on this data set to determine the degree of guessing that participants showed for different sentence types. Again, Submodel 4 of the 2HT multinomial model of source monitoring was the most parsimonious submodel that fit the data from all experimental conditions, indicating that (1) item recognition was equal for items from the two sources and new items, (2) source memory was equal for both sources, and (3) the probability of guessing "doctor" or "lawyer" was equal for recognized and unrecognized items. Parameter estimates, confidence intervals, and goodness-of-fit indices are presented in Table 2. Figure 5 shows probabilities of source guessing. We arbitrarily designated doctor as Source A and lawyer as Source B. Thus, $g$ indicates the probability of guessing "doctor," and $1-g$ indicates the probability of guessing "lawyer." Our predictions were that parameter $g$ should be above .5 (chance level) for expected-doctor statements and below .5 for expected-lawyer statements. For equal-expectancy statements, parameter $g$ should be at chance level, that is, not significantly different from .5 . Figure 5 presents the guessing probabilities for all three types of statements.

We performed significance tests to test whether the guessing probability $g$ differed across the three types of statements. These tests indicated that guessing parameter $g$ (which represents the probability of guessing "doctor") is significantly different for the three types of statements $\left[G^{2}(2)=96.00\right]$. Expected-doctor statements were guessed "doctor" with significantly higher probability than equal-expectancy statements $\left[G^{2}(1)=19.69\right.$ ], and equal-expectancy statements were guessed "doctor" with significantly higher probability than expectedlawyer statements $\left[G^{2}(1)=17.02\right]$. Parameter $g$ was significantly higher than .5 for expected-doctor statements $\left[G^{2}(1)=32.67\right]$, significantly lower than .5 for expectedlawyer statements $\left[G^{2}(1)=70.61\right]$, and not significantly different from .5 for equal-expectancy statements $\left[G^{2}(1)=\right.$ $2.54]$. All predictions regarding the probability of guessing as dependent on the expectancy of source-item pairings were thus confirmed in this experiment.

Analyses of other multinomial model-based parameters revealed that there was no significant difference in item recognition (parameter $D$ ) and source memory (parameter $d$ ) between the expected-doctor and expected-lawyer statements. Both item recognition and source memory were higher for the equally expected statements than for the other two types of statements $\left[G^{2}(1)=22.63\right.$ for item recognition; $G^{2}(1)=5.83$ for source memory]. As noted, the good fit of Model 4 for the expected-doctor and expected-lawyer statements implies that source memory was equal for the expected and the somewhat unexpected source $\left(d_{1}=d_{2}\right)$. That is, as in Experiment 1, the perfor- 
mance advantage for expected item-source pairings as opposed to somewhat unexpected item-source pairings was due to schema-based guessing, not differences in the ability to remember the sources.

\section{DISCUSSION}

According to Johnson's (1997a; Johnson et al., 1993) theoretical framework of source monitoring, decisions in source-monitoring tasks are based on phenomenological characteristics of memories as well as on prior knowledge that is relevant to the sources. In two experiments, we tested the assumption that people draw on their prior source-relevant knowledge in source-monitoring tasks. In both experiments, items of information in a schematic domain were presented by one of two sources. The domains of schematic knowledge were scenes in Experiment 1 and professional groups in Experiment 2. In both experiments, some of the items presented by each source were expected for this source, and some of the items were expected for the other source. In Experiment 2, a condition with items that were equally expected for both sources was also included. In both experiments, we found a significant interaction between expectancy and source: Correct source identification for information was higher when it was expected for its source as opposed to somewhat unexpected for its source. These results clearly support Johnson's theoretical framework of source monitoring, which postulates that people draw on their prior knowledge when making source attributions. These results support the performance hypothesis, which states that expected information should lead to better source identification than somewhat unexpected information.

Our guessing hypothesis is supported by multinomial modeling analyses, which provided evidence that the elevated source identification for expected items relative to somewhat unexpected items was due to guessing. The multinomial analyses revealed that in both experiments, participants made schema-based guesses with greaterthan-chance probability when they could not remember which source had presented a particular item. When no schema was available (in the equal-expectancy condition of Experiment 2), on the other hand, guessing was at chance level.

The ability to remember the source independent of guessing (measured by model parameter $d$ ) was not found to be affected by schema-based expectancy in either experiment. We found a small nonsignificant effect between the parameters for a somewhat unexpected source and an expected source in Experiment 1. That is, there was better source memory for objects that had been presented with a somewhat unexpected source than with an expected source when schemas were activated at encoding. This effect was in the direction predicted by the attention hypothesis (Brewer \& Treyens, 1981; Friedman, 1979; G. R. Loftus \& Mackworth, 1978), the schema-copy-plus-tag model (Graesser \& Nakamura, 1982), and the associative model (Hastie \& Kumar, 1979; Srull, 1981). There are several possible reasons why this effect was not significant. ${ }^{2}$ First, our schema-inconsistent items were only somewhat unexpected for their source. Stronger effects might emerge if highly unexpected items are used. Further, there was no single dominant schema during acquisition, because schema type (bedroom vs. bathroom) was manipulated within participants. It is also a possibility that bathroom and bedroom schemas were not fully activated, because half of the studied items were somewhat unexpected for their source. Further research is needed before a definitive conclusion can be reached as to the effects of schematic knowledge on source memory for unexpected and expected items.

A number of theoretical questions are still unanswered regarding the processes through which semantic knowledge is used in source-monitoring tasks. Johnson's theoretical framework of source monitoring (e.g., Johnson et al., 1993) postulates that source monitoring is based on what she refers to as heuristic and systematic processes. Heuristic processes are fast and nondeliberate, while systematic processes are extended reasoning processes that are more deliberate and time-consuming than heuristic processes. It is feasible that prior knowledge is used in both heuristic and systematic processes that aid in source monitoring. We know from research on social stereotypes that person schemas can be activated automatically (Devine, 1989). We also know that scene schemas can be used to guide automatic processing and more effortful processing of information (Friedman, 1979). A schema might thus be activated rapidly and automatically in a source-monitoring task and influence responses without conscious deliberation on the part of the participant. It is also conceivable that participants make a deliberate effort to draw on their prior knowledge ("Given what I know about doctors, is this a plausible statement for a doctor?"). It remains to be investigated under which circumstances people draw on which processes in their use of prior knowledge in source monitoring. In our paradigm, participants might have used either heuristic or systematic processes when using schematic knowledge, or both. A possible avenue for future research on this issue is the use of a signal-to-respond technique (Johnson, Kounios, \& Reeder, 1994; Reed, 1973). In this technique, participants are forced to give a response after specified time intervals (e.g., $300 \mathrm{msec}, 600 \mathrm{msec}$ ) that are varied between items. The time course of cognitive processes can then be investigated by plotting measures for these processes as a function of the amount of time that the participants had available for their responses. The technique could be used to study the time course of processes that use prior knowledge in source-monitoring tasks. Do retrieval processes from episodic memory and guessing processes that draw on semantic memory occur simultaneously, or does one of them occur before the other? For example, participants in our paradigm might search their memories for characteristics that they could use as a cue to the source, and when they have reached a certain criterion of invested search effort without finding clear ev- 
idence for one or the other source, they might resort to schematic knowledge to reach a response. Alternatively, when a schema is activated, participants might make an immediate guess based on the schema, without expending much effort to search for phenomenal characteristics of memories. Johnson and Raye (1981) stated that people might use different processes depending on the specific situation: "Which processes play the predominant role in a particular decision should depend on such factors as the amount of time a person has, availability of additional information in memory, and the cost of mistakes" (p. 72).

Although our experiments were not set up to directly test these issues, we observed a data pattern in Experiment 2 that is compatible with the notion that participants might adopt different criteria for the use of different kinds of information in different experimental conditions. In this experiment, we used three types of statements, namely those that are expected for their source (expected statements), those that are somewhat unexpected for their source (somewhat unexpected statements), and those that are of equal expectancy for both possible sources (equally expected statements). We observed that source identification (as measured by ACSIM) for the equally expected and the expected statements was equal, whereas source identification for the somewhat unexpected statements was significantly lower. The lack of advantage for the expected statements over the equally expected statements appears to contradict our performance hypothesis, because if source identification is based on memory and correct guessing when people can draw on a schema (expected statements) and on memory only when no schema is available (neutral, equally expected statements), then source identification should be better for expected statements than equally expected statements. This issue can be addressed by performing multinomial modeling analyses. Disentangling memory and guessing contributions to ACSIM via multinomial modeling revealed that the high source identification for the equally expected statements and the expected statements was due to different processes. Source memory was higher for the equally expected statements than for the expected statements (see parameter $d$ in Table 2). On the other hand, for the expected statements people showed a stronger guessing bias (see parameter $g$ in Table 2, indicating the probability of guessing "doctor"). This means that for the equalexpectancy statements, people reach a high ACSIM because they remember well, whereas for the expected statements, they reach a high ACSIM because they guess well. Thus, the guessing hypothesis is supported by the guessing advantage for expected statements. In addition to a difference in guessing, however, there is also a difference in memory favoring the equally expected statements. This memory advantage for equally expected statements offsets the guessing advantage for expected statements. A possible explanation for the memory advantage is that for the equally expected statements, participants might put more effort into retrieval processes. They cannot draw on a schema, and thus all they have available to reach a judgment are phenomenal characteristics of memories. They use these as best they can. For the expected statements, on the other hand, they have schemas to draw on in addition to perceptual, spatial (etc.) characteristics of memories. When a test item fits a schema, they might adopt a more lax criterion for their judgments. For example, if they find evidence in memory for the doctor being the source of an expected-doctor statement, they might not search any further for confirming or disconfirming evidence, because the evidence they found fits their prior belief about what a doctor would say. Reder (1982) expressed a similar idea regarding the dominance of plausibility judgments over memory retrieval in sentence verification. The stated interpretation of our data also fits the data pattern for those statements that were somewhat unexpected for their source. For these statements, participants made significantly more source-identification errors than for the expected and equally expected statements. That is, expecteddoctor items presented by the lawyer were with high likelihood attributed to the doctor, and vice versa. As the multinomial analyses reveal, both memory and guessing processes are responsible for the low performance for these statements. Participants do not thoroughly search for source-relevant phenomenal characteristics of memories, but instead make schema-based guesses. This interpretation of our data accords with Johnson's (1997b) hypothesis that criteria for acceptance of a memory are "more lax if a memory fits with what one already believes or wants to believe than if it does not" (p. 1734).

Several studies have shown that people adopt different criteria in source-monitoring tasks dependent on the format of the test questions (Dodson \& Johnson, 1993; Lindsay \& Johnson, 1989; Multhaup, 1995; Multhaup, DeLeonardis, \& Johnson, 1999; Zaragoza \& Lane, 1994). For example, Dodson and Johnson presented participants with scene pictures and with text passages describing scenes some of which had been shown as pictures, but many of which had not. They found that people had a high rate of false source identification when they were later asked which scenes they had seen as pictures and which not, but a lower rate of false source identification when they were asked if a given test item had been presented as a picture, in the text, both, or not at all. These results demonstrate that people adjust their response criteria depending on test conditions. The results of our study suggest that people may also adjust their memory search and response criteria depending on their background knowledge about sources. When there is no background knowledge that can aid in source attributions, criteria for a memory search might be more stringent.

An alternative to the interpretation that participants put more effort into retrieval processes when no relevant schemas are available is the interpretation that depending on schema availability, participants may assign different weights to different types of available information. When 
a schema is available, they may give more weight to this schema than to characteristics of memories such as perceptual information, even if the latter information is also available. ${ }^{3}$

A possible objection to both these interpretations of the data of Experiment 2 is that in the three conditions (expected doctor, expected lawyer, equally expected), different sentence items were used. It is possible that the equally expected and the expected sentences differed with regard to characteristics other than expectancy (e.g., length of sentences, familiarity). If such characteristics increase the source memory for equally expected sentences, they could present an alternative explanation for our data pattern. In fact, for equally expected sentences, participants not only have higher source memory (model parameter $d$ ) than for the other sentences, but also have higher item recognition (model parameter $D$ ). The increased item recognition could be a result of higher memorability of the equally expected sentences, but it could also be a result of increased memory search processes on the part of the participants. Our data can thus not be interpreted unambiguously with regard to the issue of the dominance of memory versus schema-based-guessing processes in different conditions, and this issue needs further investigation.

Another important theoretical issue addressed by our research is the question of what point in time schemas need to be activated so that they can be used for source judgments. In Experiment 1, scene schemas were activated at the time of encoding through the presentation of scene labels. These scene labels were also present at the time of retrieval. In Experiment 2, on the other hand, participants were not told until after the encoding phase which professional groups the two sources belonged to. It is possible that the sentences themselves led to schema activation during encoding. However, participants could not make a clear assignment of the sources to schemas at the time of encoding, because the expected-doctor and the expectedlawyer sentences had equal likelihood of being presented by "Tom" and "Jim." It was thus the schema activated at retrieval that determined the participants' guessing patterns in this experiment. The association of a source with a schema at the time of retrieval is thus sufficient for schema-based source judgments.

This leads us to the practical implications of our research. In court cases, for example, it is often important for participants such as witnesses and jurors to attribute information to the correct source, whether this source be a person (e.g., "Was it the defendant who said this?" "Which attorney presented this argument?") or a scene (e.g., "Was the bloody glove at the crime scene?"). On the basis of our research, one would expect that the schemas activated by such persons and situations would influence source judgments. In cases where information presented by a source fits into the schema of this source, the schema will be used to guess the correct source, but at the cost that if a source presents information that fits the schema of an alternative possible source, this schema will be used to guess the incorrect source. Thus, in cases where the in- formation does not fit into the schema of its source, errors with serious implications can occur. As our research shows, schema activation at the time of retrieval (e.g., in court) is sufficient to trigger biases in people that can lead to errors in source judgments. This lends further support to the finding that schemas activated through questioning after an event can greatly influence the responses of eyewitnesses (E. F. Loftus \& Palmer, 1974).

Our experiments show that in accordance with Johnson's theory, people use prior knowledge in source monitoring, and that schema-based guessing plays a large role in the influence that schematic knowledge has on source monitoring. More research is needed to further interface the prior-knowledge and the source-monitoring research areas and to shed further light on the processes by which prior knowledge is used in source monitoring.

\section{REFERENCES}

AlBa, J. W., \& HASher, L. (1983). Is memory schematic? Psychological Bulletin, 93, 203-231.

Anderson, R. C., \& Pichert, J. W. (1978). Recall of previously unrecallable information following a shift in perspective. Journal of Verbal Learning \& Verbal Behavior, 17, 1-12.

BatChelder, W. H., Hu, X., \& RiefER, D. M. (1994). Analysis of a model for source monitoring. In G. H. Fisher \& D. Laming (Eds.), Contributions to mathematical psychology, psychometrics, and methodology (pp. 51-64). New York: Springer-Verlag.

BatCHELDER, W. H., \& RiEfER, D. M. (1980). Separation of storage and retrieval factors in free recall of clusterable pairs. Psychological Review, 87, 375-397.

BatChelder, W. H., \& Riefer, D. M. (1990). Multinomial processing models of source monitoring. Psychological Review, 97, 548-564.

BatCHELder, W. H., RiEfER, D. M., \& Hu, X. (1994). Measuring memory factors in source monitoring: Reply to Kinchla. Psychological Review, 101, 172-176.

Bayen, U. J., \& Murnane, K. (1996). Aging and the use of perceptual and temporal information in source memory tasks. Psychology \& Aging, 11, 293-303.

Bayen, U. J., Murnane, K., \& Erdfelder, E. (1996). Source discrimination, item detection, and multinomial models of source monitoring. Journal of Experimental Psychology: Learning, Memory, \& Cognition, 22, 197-215.

Bender, R. H., Wallsten, T. S., \& Ornstein, P. A. (1996). Age differences in encoding and retrieving details of a pediatric examination. Psychonomic Bulletin \& Review, 3, 188-198.

Bornstein, B. H., \& LeCompte, D. C. (1995). A comparison of item and source forgetting. Psychonomic Bulletin \& Review, 2, 254-259.

Brewer, W. F, \& Treyens, J. C. (1981). Role of schemata in memory for places. Cognitive Psychology, 13, 207-230.

DevinE, P. G. (1989). Stereotypes and prejudice: Their automatic and controlled components. Journal of Personality \& Social Psychology, 56, 5-18.

Dodson, C. S., \& Johnson, M. K. (1993). The rate of false source attributions depends on how questions are asked. American Journal of Psychology, 106, 541-557.

ERdFELder, E., \& BREDENKAMP, J. (1998). Recognition of script-typical versus script-atypical information: Effects of cognitive elaboration. Memory \& Cognition, 26, 922-938.

ERDFELDER, E., \& BUCHNER, A. (1998). Decomposing the hindsight bias: A multinomial processing tree model for separating recollection and reconstruction in hindsight. Journal of Experimental Psychology: Learning, Memory, \& Cognition, 24, 387-414.

ERnGRUnd, K., MäNTYLÄ, T., \& NilsSON, L.-G. (1996), Adult age differences in source recall: A population-based study. Journal of Gerontology: Psychological Sciences, 51 B, P335-P345.

Friedman, A. (1979). Framing pictures: The role of knowledge in au- 
tomatized encoding and memory for gist. Journal of Experimental Psychology: General, 108, 316-355.

Glisky, E. L., Poster, M. R., \& Routhieaux, B. C. (1995). Double dissociation between item and source memory. Neuropsychology, 9 , 229-235.

Graesser, A. C., Gordon, S. E., \& SAwyers, J. D. (1979). Recognition memory for typical and atypical actions in scripted activities: Tests of a script pointer + tag hypothesis. Journal of Verbal Learning \& Verbal Behavior, 18, 319-322.

Graesser, A. C., \& Nakamura, G. V. (1982). The impact of a schema on comprehension and memory. In G. H. Bower (Ed.), The psychology of learning and motivation (Vol. 16, pp. 59-109). New York: Academic Press.

Graesser, A. C., Woll, S. B., Kowalski, D. J., \& Smith, D. A. (1980) Memory for typical and atypical actions in scripted activities. Jour nal of Experimental Psychology: Human Learning \& Memory, 6 , 503-515.

HASTIE, R. (1980). Memory for behavioral information that confirms or contradicts a personality impression. In R. Hastie, T. Ostrom, E. Ebbesen, R. S. Wyer, D. L. Hamilton, \& D. Carlston (Eds.), Person memory: The cognitive basis of social perception (pp. 155-177). Hillsdale, NJ: Erlbaum.

Hastie, R., \& Kumar, P. A. (1979). Person memory: Personality traits as organizing principles in memory for behaviors. Journal of Personality \& Social Psychology, 37, 25-38.

$\mathrm{HU}, \mathrm{X}$. (1991). Statistical inference program for multinomial binary tree models (Version 1.0) [Computer program]. Irvine: University of California.

Hu, X., \& BATCHELDER, W. H. (1994). The statistical analysis of general processing tree models with the EM algorithm. Psychometrika, 59, $21-47$.

Hyman, I. E., Husband, T. H., \& Billings, F. J. (1995). False memories of childhood experiences. Applied Cognitive Psychology, 9, 181197.

Johnson, M. K. (1997a). Identifying the origin of mental experience. In M. S. Myslobodsky (Ed.), The mythomanias: The nature of de ception and self-deception (pp. 133-180). Mahwah, NJ: Erlbaum.

JohNSON, M. K. (1997b). Source monitoring and memory distortion Philosophical Transactions of the Royal Society of London: Series B, 352, 1733-1745.

Johnson, M. K., Deleonardis, D. M., Hashtroudi, S., \& Ferguson, S. A. (1995). Aging and single versus multiple cues in source monitoring. Psychology \& Aging, 10, 507-517.

Johnson, M. K., Foley, M. A., Suengas, A. G., \& Raye, C. L. (1988) Phenomenal characteristics of memories for perceived and imagined autobiographical events. Journal of Experimental Psychology: General, 117, 371-376

Johnson, M. K., Hashtroudi, S., \& Lindsay, D. S. (1993). Source monitoring. Psychological Bulletin, 114, 3-28.

Johnson, M. K., Kounios, J., \& Reeder, J. A. (1994). Time-course studies of reality monitoring and recognition. Journal of Experimental Psychology: Learning, Memory, \& Cognition, 20, 1409-1419.

Johnson, M. K., \& RAYE, C. L. (1981). Reality monitoring. Psychological Review, 88, 67-85.

KeEfe, R. S. E., ARNold, M. C., Bayen, U. I., \& Harvey, P. D. (1999) Source monitoring deficits in patients with schizophrenia: A multinomial modeling analysis. Psychological Medicine, 29, 903-914

KINCHLA, R. A. (1994). Comments on Batchelder and Riefer's multinomial model for source monitoring. Psychological Review, 101, 166-171

KINTSCH, W. (1970). Learning, memory, and conceptual processes. New York: Wiley.

LindSAY, D. S., \& Johnson, M. K. (1989). The eyewitness suggestibility effect and memory for source. Memory \& Cognition, 17, 349-358

locksley, A., Stangor, C., Hepburn, C., Grosovsky, E., \& HochSTRASSER, M. (1984). The ambiguity of recognition memory tests of schema theories. Cognitive Psychology, 16, 421-448

LofTus, E. F. \& PALMER, J. C. (1974). Reconstruction of automobile destruction: An example of the interaction between language and memory. Journal of Verbal Learning \& Verbal Behavior, 13, 585-589.

LofTUS, G. R., \& MACKwORTH, N. H. (1978). Cognitive determinants of fixation location during picture viewing. Journal of Experimental Psychology: Human Perception \& Performance, 4, 565-572.

Mather, M., Johnson, M. K., \& DeLeonardis, D. M. (1999). Stereotype reliance in source monitoring: Age differences and neuropsychological test correlates. Cognitive Neuropsychology, 16, 437-458.

Multhaup, K. S. (1995). Aging, source, and decision criteria: When false fame errors do and do not occur. Psychology \& Aging, 10, 492497.

Multhaup, K. W., Deleonardis, D. M., \& Johnson, M. K. (1999). Source memory and eyewitness suggestibility in older adults. Journal of General Psychology, 126, 74-84.

Murnane, K., \& BAYEN, U. J. (1996). An evaluation of empirical measures of source identification. Memory \& Cognition, 24, 417-428.

Nakamura, G. V., Graesser, A. C., Zimmerman, J. A., \& Riha, J. (1985). Script processing in a natural situation. Memory \& Cognition, 13, 140-144.

Pezdek, K., Whetstone, T., Reynolds, K., Askari, N., \& DougherTy, T. (1989). Memory for real-world scenes: The role of consistency with schema expectation. Journal of Experimental Psychology: Learning. Memory, \& Cognition, 15, 587-596.

REDER, L. (1982). Plausibility judgments versus fact retrieval: Alternative strategies for sentence verification. Psychological Review, 89 , $250-280$

REED, A. V. (1973). Speed-accuracy trade-off in recognition memory. Science, 181, 574-576.

Riefer, D. M., \& BATCHELder, W. H. (1988). Multinomial modeling and the measurement of cognitive processes. Psychological Review, 95, 318-339.

Schacter, D. L., Osowiecki, D., Kaszniak, A. W., Kihlstrom, J. F., \& VALDISERRI, M. (1994). Source memory: Extending the boundaries of age-related deficits. Psychology \& Aging, 9, 81-89.

SCHWEICKERT, R. (1993). A multinomial processing tree model for degradation and redintegration in immediate recall. Memory \& Cognition, 21, 168-175.

Sherman, J, W., \& Bessenoff, G. R. (1999). Stereotypes as source monitoring cues: On the interaction between episodic and semantic memory. Psychological Science, 10, 106-110.

SMith, D. A., \& GRaEsSer, A. C. (1981). Memory for actions in scripted activities as a function of typicality, retention interval, and retrieval task. Memory \& Cognition, 9, 550-559.

SNodgrass, J. G., \& Corwin, J. (1988). Pragmatics of measuring recognition memory: Applications to dementia and amnesia. Journal of Experimental Psychology: General, 117, 34-50.

SRULL, T. K. (1981). Person memory: Some tests of associative storage and retrieval models. Journal of Experimental Psychology: Human Learning \& Memory, 7, 440-462.

Srull, T. K., Lichtenstein, M., \& Rothbart, M. (1985). Associative storage and retrieval processes in person memory. Journal of $E x$ perimental Psychology: Learning, Memory, \& Cognition, 11, 316345 .

ZaRAGOZA, M. S., \& LANE, S. M. (1994). Source misattributions and the suggestibility of eyewitness memory. Journal of Experimental Psychology: Learning, Memory, \& Cognition, 20, 934-945.

\section{NOTES}

1. During the review process, we learned that Mather, Johnson, and DeLeonardis (1999) and Sherman and Bessenoff (1999) have recently developed paradigms, independent of our research, in which they manipulated the degree to which combinations of source and originating information conform to prior knowledge. In both studies, it was found that people use prior knowledge to attribute memories to sources

2 . We thank an anonymous reviewer for pointing this out.

3. We thank Marcia Johnson for pointing out this possibility. 


\begin{tabular}{|c|c|c|}
\hline \multicolumn{3}{|c|}{$\begin{array}{c}\text { APPENDIX A } \\
\text { Items Used in Experiment } 1\end{array}$} \\
\hline Item Group & $\begin{array}{c}\text { Expected Bedroom/ } \\
\text { Somewhat Unexpected Bathroom }\end{array}$ & $\begin{array}{c}\text { Expected Bathroom/ } \\
\text { Somewhat Unexpected Bedroom }\end{array}$ \\
\hline 1 & $\begin{array}{l}\text { jewelry } \\
\text { shoes } \\
\text { lamp } \\
\text { radio } \\
\text { chest } \\
\text { books }\end{array}$ & $\begin{array}{l}\text { sink } \\
\text { soap } \\
\text { toilet paper } \\
\text { shampoo } \\
\text { toothpaste } \\
\text { hairdryer }\end{array}$ \\
\hline 2 & $\begin{array}{l}\text { blankets } \\
\text { nightstand } \\
\text { clothes } \\
\text { stuffed animals } \\
\text { closet } \\
\text { sheet }\end{array}$ & $\begin{array}{l}\text { shaving cream } \\
\text { mouthwash } \\
\text { hairspray } \\
\text { medicine } \\
\text { lotion } \\
\text { curling iron }\end{array}$ \\
\hline 3 & $\begin{array}{l}\text { carpet } \\
\text { ceiling fan } \\
\text { pictures } \\
\text { clock } \\
\text { television } \\
\text { telephone }\end{array}$ & $\begin{array}{l}\text { razor } \\
\text { deodorant } \\
\text { washcloth } \\
\text { towels } \\
\text { conditioner } \\
\text { toothbrush }\end{array}$ \\
\hline
\end{tabular}

\begin{tabular}{|c|c|c|c|c|c|c|}
\hline \multicolumn{7}{|c|}{$\begin{array}{l}\text { APPENDIX B } \\
\text { Frequencies of Responses to Items Presented With Bedroom, } \\
\text { Items Presented With Bathroom, and New Items Under } \\
\text { Different Conditions of Expectancy in Experiment } 1\end{array}$} \\
\hline & \multicolumn{6}{|c|}{ Expectancy of Items } \\
\hline & \multicolumn{3}{|c|}{ Bedroom } & \multicolumn{3}{|c|}{ Bathroom } \\
\hline Source & "Bedroom" & "Bathroom" & "Neither" & "Bedroom" & "Bathroom" " & "Neither" \\
\hline Bedroom & 335 & 24 & 37 & 252 & 118 & 26 \\
\hline Bathroom & 65 & 301 & 30 & 45 & 332 & 19 \\
\hline New & 46 & 8 & 342 & 19 & 59 & 318 \\
\hline
\end{tabular}

Note-Responses are in quotation marks.

APPENDIX C

Items Used in Experiment 2

\begin{tabular}{cl}
\hline Target Items & Distractor Items \\
\hline
\end{tabular}

\section{Expected Doctor}

1. Are you taking any other medicine?

2. Be sure to take all of your prescription.

3. Do you have any food allergies?

4. Don't drink caffeine with this.

5. Get at least eight hours of sleep.

6. Heredity may play a small part in some chronic, degenerative diseases.

7. Hot baths will help the soreness.

8. How long have you been sick?

9. How long have you had fever?

10. I don't suggest you leave the hospital for another several hours.
Are you taking any other prescriptions?

Be sure to stop taking your prescription.

Do you have any drug allergies?

Don't drink alcohol with this.

Get at least six hours of sleep.

Heredity may play a large part in many chronic, degenerative diseases.

Hot showers will help the soreness.

How long have you been well?

How long have you had symptoms?

I don't suggest you leave the hospital before tomorrow. 
APPENDIX C (Continued)

Target ltems
11. I'll come talk to you as soon as I wash up.
12. If you don't feel better in 24 hours, come in
to my office.
13. In my experience, this procedure has been
very effective.
14. Is this problem keeping you awake at night?
15. It will take a couple of hours to get the
results of this blood test.
16. Keep your sprained ankle propped up.
17. Let me see the x-ray of his head.
18. Stay in bed for two weeks.
19. Take two aspirins and call me in the
morning.
20. Tell me where it hurts.
21. The cast can come off next month.
22. This is a very delicate procedure.
23. We'll have to take some urine samples before
we know for sure.
24. We've already run some tests.
25. What are your symptoms?
26. You eat too many salty foods.
27. When did you start sneezing?
28. You have a broken wrist.
29. You need a heart transplant.
30. You need an EEG.
31. You will have a heart attack if you don't lose
32. You'll need to see a specialist.

Distractor Items

I'll come talk to you as soon as I scrub up.

If you don't feel better in 24 hours, call my office.

In my experience, this medication has been very effective.

Is this problem making it hard to wake up? It will take a couple of minutes to get the results of this blood test.

Keep your broken leg propped up.

Let me see the X-ray of his chest.

Stay inside for two weeks.

Take two of these and call me in the morning.

Does that hurt?

The cast can come off next week.

This is a very common procedure.

We'll have to do some bloodwork before we know for sure.

We'll have to run some tests.

What are the side effects?

You eat too many sweet fuods.

When did you start coughing?

You have a broken arm.

You need a kidney transplant.

You need an EKG.

You have had a heart attack.

You'll need to see my partner.

Expected Lawyer

1. I ask that custody be given to the mother.

I ask that custody be give to the grandparents.

2. The lawsuit was settled for my client pertaining to the automobile accident.

3. I ask the jury to acquit this man.

I will be filing a lawsuit for my client pertaining to an automobile accident. I ask the jury to hang this man.

4. The state is not going to offer a plea bargain.

5. I need to get that case to you as soon as possible.

6. The trial date has been postponed.

7. I do not have to prepare a deposition for the client.

8. That will be a very interesting case to argue.

9. Your client's whereabouts are accounted for on the day in question.

10. Do you see the gentleman in this courtroom?

11. I object. That is just circumstantial evidence.

12. I have to be in court at 9:00.

13. I meet with the judge today at 3:00.

14. Who do you accuse of stealing your car?

15. The child's custody was awarded to his father.

16. Did you kill him with this knife?

17. We'll ask for one million.

18. Were there any other suspects of the crime?

19. His testimony will be useful to the prosecution.

20. I have a deposition tomorrow.

21. States are required to provide council if the plaintiff can not afford it.

22. You face a fine of $\$ 500$.

23. The trial is set for 9:00 a.m.

The state wants to offer a plea bargain of two years.

I need to get that brief drawn up as soon as possible.

The trial date has been moved up.

I have to prepare a deposition for the client.

That will be a very difficult case to argue. Your client's whereabouts aren't accounted for on the day in question.

Do you know the gentleman in the corner?

I object. That is just hearsay.

I have to be at school at 9:00.

I meet with the judge tomorrow at 3:00.

Who do you accuse of vandalizing your car?

The child's custody was awarded to his mother.

Did you kill him with this gun?

We'll ask for five million.

Were there any other witnesses to the crime? His testimony will be useful to the defense.

I had a deposition yesterday.

States were required to provide council if the defendant could not afford it.

You face a fine of $\$ 1000$.

The trial is set for 10:00 a.m. 
APPENDIX C (Continued)

\begin{tabular}{|c|c|}
\hline Target Items & Distractor Items \\
\hline $\begin{array}{l}\text { 24. The witness will be hurt if not put under the } \\
\text { witness protection program. }\end{array}$ & $\begin{array}{l}\text { I request the witness be under the witness } \\
\text { protection program. }\end{array}$ \\
\hline 25. The defendant pleaded not guilty. & The defendant was found not guilty. \\
\hline 26. Did you murder Jack? & Did you murder Jack's wife? \\
\hline 27. I was granted a continuance on this case. & I was not granted a continuance on this case. \\
\hline $\begin{array}{l}\text { 28. I have to go through jury selection in court } \\
\text { tomorrow. }\end{array}$ & $\begin{array}{l}\text { I have to go through jury selection in court } \\
\text { today. }\end{array}$ \\
\hline 29. We'll win this case. & We'll lose this case. \\
\hline 30. Let me get your statement. & Let's go over your testimony. \\
\hline 31. Do you accuse him of assault and battery? & Who was it that assaulted you? \\
\hline 32. Her act was in self-defense. & Killing him was in self-defense. \\
\hline
\end{tabular}

\section{Equal Expectancy}

1. I have never liked spinach.

2. I have a date tomorrow night.

3. I persuaded the salesperson to drop $\$ 10$ off the price of this jacket.

4. I decided to take a Tak Won Do class to learn self-defense.

5. I love to listen to Mel Torme.

6. I need to take my car to the garage for an oil change.

7. Have a seat in my office.

8. I lost my wallet.

9. I can't stand people who are too quiet.

10. We are having a dinner party next Friday.

11. I moved to this city about ten years ago.

12. Let's have dinner.

13. My son goes to Harvard.

14. I've heard the Warhol exhibit is coming to the museum soon.

15. I've been reading a fascinating new novel.

16. I'm a member of several professional organizations.

17. I have to fly to New York this weekend.

18. Tomorrow is my 25 th anniversary.

19. I graduated from college in 1972 .

20. I'm a member of a yachting club.

21. I must admit, I'm very good at chess.

22. I must get my son's car inspected tomorrow

23. I took a few years of French in college, but I never learned to speak it well.

24. I have to go in to the office early today.

25. I'm afraid I annoy my neighbors by trimming hedges so early in the morning.

26. I love to play tennis.

27. I don't have a wonderful singing voice.

28. I need to look at my calendar.

29. I saw the dentist yesterday about my tooth.

30. I spilled soup on my lapel.

31. I always go to the gas station on main street.

32. I'll be skiing in Vermont over the Christmas holidays.
I have never liked broccoli.

I have a date tonight.

I persuaded the salesperson to drop $\$ 30$ off the price of this jacket.

I decided to take a Judo class to learn self-

defense.

I love to listen to Wayne Newton.

I need to take my car to the garage for

alignment.

Have a seat in my waiting room.

I lost my briefcase.

I can't stand people who talk incessantly.

We are having a cocktail party next Friday.

I moved to this city about twenty years ago.

Let's have lunch.

My daughter goes to Harvard.

l've heard the Monet exhibit is coming to the museum soon.

l've been reading a fascinating new

biography.

I'm a member of several charity

organizations.

I have to fly to Los Angeles this weekend.

Tomorrow is my 30th anniversary.

I graduated from high school in 1972.

I'm a member of a country club.

I must admit, I'm very good at checkers.

I must get my car inspected tomorrow.

I took a few years of German in college, but

I never learned to speak it well.

I have to go in to the office early next week.

I'm afraid I annoy my neighbors by mowing so early in the morning.

I love to play golf.

I have a wonderful singing voice.

I need to look at my address book.

I need to see the dentist about this tooth.

I spilled soup on my tie.

I always go to the gas station on second street.

I'll be skiing in Colorado over the Christmas holidays. 
APPENDIX D

Frequencies of Responses to Items Presented by Doctor, Items Presented by Lawyer, and New Items Under Different Conditions of Expectancy in Experiment 2

\begin{tabular}{|c|c|c|c|c|c|c|c|c|c|}
\hline \multirow[b]{3}{*}{ Source } & \multicolumn{9}{|c|}{ Expectancy of Items } \\
\hline & \multicolumn{3}{|c|}{ Expected Doctor } & \multicolumn{3}{|c|}{ Expected Lawyer } & \multicolumn{3}{|c|}{ Equal-Expectancy } \\
\hline & "Doctor" & "Lawyer" & "Neither" & "Doctor" & "Lawyer" & "Neither" & "Doctor" & "Lawyer" & "Neither" \\
\hline Doctor & 102 & 41 & 49 & 45 & 87 & 60 & 104 & 43 & 45 \\
\hline Lawyer & 79 & 68 & 45 & 27 & 101 & 64 & 42 & 105 & 45 \\
\hline New & 103 & 57 & 224 & 53 & 101 & 230 & 43 & 59 & 282 \\
\hline
\end{tabular}

Note-Responses are in quotes. 